Esta obra está bajo una Licencia Creative Commons Atribución-

NoComercial-CompartirIgual 4.0 internacional

Arte rupestre y biogeografía humana en el norte del Neuquén (Patagonia): lineamientos conceptuales para el estudio multiescalar de procesos de comunicación visual y circulación de información

Guadalupe Romero Villanueva

Relaciones, 46(2), e021, julio-diciembre 2021

ISSN 1852-1479 | https://doi.org/10.24215/18521479e021

https://revistas.unlp.edu.ar/relaciones

ISSN 0325-2221 (versión impresa)

Sociedad Argentina de Antropología (SAA)

Buenos Aires I Argentina

\title{
ARTE RUPESTRE Y BIOGEOGRAFÍA HUMANA EN EL NORTE DEL NEUQUÉN (PATAGONIA): LINEAMIENTOS CONCEPTUALES PARA EL ESTUDIO MULTIESCALAR DE PROCESOS DE COMUNICACIÓN VISUAL Y CIRCULACIÓN DE INFORMACIÓN
}

Guadalupe Romero Villanueva*

Fecha de recepción: 30 de diciembre de 2020

Fecha de aceptación: 11 de julio de 2021

\section{RESUMEN}

Se presenta una perspectiva multiescalar de base biogeográfica para el estudio arqueológico sistemático de procesos de comunicación visual y circulación de información mediante arte rupestre. Se proveen definiciones operativas de los componentes conceptuales del enfoque (arte rupestre, biogeografía humana, multiescalaridad). También se refiere el rol de otros elementos y marcos analíticos (modelos biogeográficos, estudios internodales, geografía social) que operan como puntos de partida y ejes estructurantes de las preguntas de investigación sobre estos procesos en el pasado. Además, se especifican temas geográficos, temporales y sociodemográficos de la organización humana pretérita de interés al enfoque propuesto. Se reseñan los resultados multiescalares alcanzados producto de su aplicación en el norte del Neuquén y se discute el potencial del enfoque para modelar los roles desempeñados y tipos de información transmitidos por el arte rupestre en las dinámicas comunicacionales que los grupos móviles del noroeste de Patagonia plasmaron en el paisaje durante el Holoceno.

Palabras clave: imágenes rupestres-sistematización-métodos formales-múltiples escalas espaciales - marcación del paisaje

\footnotetext{
* Consejo Nacional de Investigaciones Científicas y Técnicas, Instituto Nacional de Antropología y Pensamiento Latinoamericano. E-mail: gromerovillanueva@conicet.gov.ar
} 
Relaciones de la Sociedad Argentina de Antropología 46 (2), julio-diciembre 2021: 595-628

\section{ROCK ART AND HUMAN BIOGEOGRAPHY IN NORTHERN NEUQUÉN (PATAGONIA): CONCEPTUAL GUIDELINES FOR A MULTI-SCALAR APPROACH ON VISUAL COMMUNICATION AND INFORMATION EXCHANGE}

\section{ABSTRACT}

A biogeographic-basedmultiscale perspectivefor the systematic archaeological study of visual communication and information exchange processes through rock art is presented. Operational definitions of the conceptual components of the approach (rock art, human biogeography, multiscalarity) are provided. It also discusses the role of different analytical elements and frameworks (biogeographic models, internodal studies, social geography) that work as starting points and structuring axes of research questions on these processes in the past. Additionally, geographical, temporal and socio-demographic aspects of past human organization of particular interest to this proposal are also summarized. We review the multiscale results obtained from their application in northern Neuquén in order to discuss the possibilities of the approach for modeling the roles and information types transmitted through rock art within the communicational dynamics that mobile groups of northwestern Patagonia deployed over the landscape during the Holocene.

Keywords: rock art images - systematization - formal methods - multiple spatial scales landscape marking

\section{INTRODUCCIÓN}

Una de las grandes enseñanzas de los estudios arqueológicos y etnográficos sobre arte rupestre a nivel global es que, como se desarrollará más adelante, esta evidencia puede desempeñar diversos roles en las sociedades que la produjeron para comunicarse en términos visuales y materiales. En parte, esto se debe a la capacidad inherente a estas imágenes de transmitir distintos tipos de información, incluso en forma simultánea, de acuerdo a múltiples factores (por ej. propiedades formales, escala, contexto de uso). Así, su estudio conlleva el desafío de incorporar esta potencial versatilidad en la generación de datos rupestres sistemáticos que permitan elaborar lecturas concordantes con la complejidad de los procesos comunicacionales bajo estudio. Sin embargo, las miradas analíticas empleadas en la generación y posterior discusión del dato rupestre, también son versátiles ya que varían de acuerdo con el marco teórico-metodológico de quien investiga, sus preguntas de partida y las características del caso bajo estudio, entre otros factores. Por ello, siempre resulta de interés a la comunidad académica la publicación de trabajos donde se explicitan vías analíticas particulares para el análisis del arte rupestre que no solo contribuyen a encuadrar teórica y metodológicamente los datos resultantes, sino que ofrecen la información necesaria para replicar, en otros casos de estudio, aquellas miradas consideradas útiles.

Sobre esta base, el objetivo de este trabajo es sintetizar los principales lineamientos conceptuales de una propuesta de base biogeográfica para desarrollar un análisis arqueológico sistemático sobre procesos de comunicación visual y circulación de información mediante el estudio multiescalar del arte rupestre. En primer lugar, se proveen definiciones operativas de los componentes conceptuales clave del enfoque -la biogeografía humana y el arte rupestre- y se plantean las articulaciones analíticas propuestas para vincularlos. Seguidamente, se destaca el rol de otros elementos conceptuales, tales como diversos modelos biogeográficos y marcos de trabajo como los Estudios Internodales y la Geografía Social, que operan como puntos de partida para la generación de preguntas de investigación y expectativas materiales. Luego, se mencionan brevemente las estrategias metodológicas relevantes para la implementación del enfoque que permiten explorar, en forma sistemática, el potencial carácter multiescalar del arte rupestre. Por último, se provee un 
ejemplo de aplicación de la propuesta al corpus rupestre de la Localidad Barrancas-Buta Ranquil (en adelante LBB), ubicada en el norte de la provincia del Neuquén (Patagonia, Argentina). Los resultados alcanzados son reseñados para enfatizar la discusión de temas geográficos, temporales y sociodemográficos vinculados con la producción, el uso y los potenciales roles desempeñados por las imágenes rupestres bajo estudio en distintas escalas y contextos.

La propuesta aquí presentada comenzó a ser delineada y aplicada hace varios años (Barberena 2013; Romero y Re 2014; Barberena et al. 2015a, 2017; Romero Villanueva y Barberena 2015, 2017; Belardi et al. 2016; Romero Villanueva 2016). Luego, fue revisada, ampliada, sistematizada y explicitada en la tesis doctoral inédita de la autora donde se aplicó al caso del arte rupestre de la LBB (Romero Villanueva 2019a). Esta aplicación permitió desarrollar un acercamiento multiescalar sistemático, además de teórica y metodológicamente orientado, al modelado de los roles desempeñados y tipos de información transmitidos por el arte rupestre de la LBB en la dinámica comunicacional y de marcación del paisaje implementada por los grupos móviles del noroeste de Patagonia durante el Holoceno y, en particular, en el Holoceno tardío. En esta oportunidad, no se presentan los resultados detallados de este análisis -tarea ya comenzada y que se continúa en otros trabajos (Romero Villanueva 2019b, 2021; Romero Villanueva et al. 2020, 2021a, b, c y d; Rughini et al. 2020; Romero Villanueva y Barberena 2021)-, sino que serán reseñados brevemente a fin de ilustrar el potencial heurístico multiescalar de la propuesta, de acuerdo con el objetivo de este trabajo.

\section{LA MIRADA CONCEPTUAL: EL ENTRAMADO DE LA BIOGEOGRAFÍA HUMANA CON EL ARTE RUPESTRE}

\section{Definiciones operativas y temas de interés en escala arqueológica}

La biogeografía consiste en analizar las pautas de conducta y distribución espacial y temporal de poblaciones de organismos en relación con las propiedades del paisaje que habitan, e implica evaluar la influencia que éste ejerce en las características de procesos históricos de largo plazo (Lahr y Foley 1998; Lomolino et al. 2010). Dado su énfasis distribucional y evolutivo, el paisaje -su configuración y sus cambios- ocupa un rol analítico clave. En particular, la biogeografía humana considera a las poblaciones humanas como un componente más de los ecosistemas (Terrell 2006; Harcourt 2012; Gjesfjeld et al. 2020). Así, el espacio es la dimensión en la que se evalúa la intersección entre las trayectorias humanas de cambio biológico y cultural (Borrero 1989-90; Veth 1993; Harcourt 2012). Sobre la base de estos aportes, desde la perspectiva aquí adoptada se concibe a la biogeografía humana como una instancia teórica de rango medio que provee conceptos y herramientas metodológicas para articular en forma coherente las distintas líneas de evidencia arqueológica documentadas en una región y con el paisaje -actual y pretérito- en el cual se emplazan (figura 1) (Barberena 2008, 2013; Belardi et al. 2016; Barberena et al. 2017).

Asimismo, se entiende por arte rupestre $^{1}$ las imágenes realizadas por los humanos en soportes rocosos naturales inamovibles (Whitley 2001; McDonald 2008; Fiore 2009). Entre otras posibles, esta definición destaca algunos aspectos -visuales, materiales y espaciales- que ocupan un rol analítico fundamental en la presente propuesta ya que permiten operativizar el estudio de imágenes rupestres en una escala arqueológica (figura 1). Por un lado, como toda imagen al mediar procesos de comunicación visual, los motivos rupestres conllevan el potencial de desempeñar variados roles en una sociedad en relación con la posibilidad de transmitir múltiples tipos de información (por ej. identitaria, religiosa, ritual, ecológica) en diversas escalas espaciales y contextos sociales (Layton 1991, 1992; Morphy 1991; McDonald y Veth 2006, 2011, 2013; Carden 2008; Fiore 2009; Re 2010; Loubser 2013; Re y Belardi 2019; Acevedo y Fiore 2020; entre otros). Por otro 
lado, el uso de la roca como soporte puede propiciar una mayor perdurabilidad de las imágenes y de la información que transmiten en el tiempo, factor que torna al arte rupestre en un fenómeno social potencialmente aditivo e interactivo (Aschero 1988; Hartley 1992; Re 2010; Charlin y Borrero 2012; Martel et al. 2012; Loubser 2013; McDonald y Veth 2013; Fiore y Acevedo 2018; Carden y Miotti 2020; entre otros), sujeto a múltiples (re)interpretaciones, recurrentes o novedosas. Asimismo, al estar ancladas de forma deliberada a determinados rasgos del paisaje, las imágenes rupestres constituyen un indicador arqueológico excepcional sobre formas pasadas de percibir, experimentar, organizar, construir, señalizar y socializar lugares significativos para los grupos humanos del pasado (Taçon 1994; Troncoso 2006, 2019; Carden 2008; Re 2010; Charlin y Borrero 2012; Langley 2013; Fiore y Acevedo 2018; Romero Villanueva 2021; Sepúlveda et al. 2019; Carden et al. 2020; entre otros).

Además de orientar teórica y metodológicamente el estudio arqueológico del arte rupestre, la perspectiva biogeográfica adoptada permite estructurar la generación de información multiescalar sistemática y enfatizar la discusión integral de ciertos temas -geográficos, temporales y sociodemográficos- cuya relevancia para un análisis biogeográfico ya ha sido resaltada (Borrero 1989-90; Gamble 1993; Lahr y Foley 1998; Barberena 2008, 2013; Romero Villanueva 2019a) (figura 1). Su importancia radica en que la discusión integral de los temas propuestos puede informar sobre la amplitud espacial y trayectoria temporal de distintas esferas de acción humana pasada (por. ej. comunicación, interacción social, movilidad, uso del espacio), al tiempo que la perspectiva multiescalar contribuye a maximizar las chances de interceptar un mayor rango de variación conductual (Borrero 2020; ver también Belardi 2020). Cabe señalar que los temas referidos se diferencian de aquellos clásicamente discutidos desde otras perspectivas biogeográficas aplicadas en la arqueología de Patagonia, tales como los procesos de especiación, la identificación de endemismos o el establecimiento de filogenias (Scheinsohn y Szumik 2007; Scheinsohn et al. 2009).

Más específicamente, desde la perspectiva biogeográfica aquí propuesta, se entiende que la fijeza espacial del arte rupestre le confiere una alta resolución para ahondar en temas geográficos con anclajes espaciales precisos (figura 1). Así, el análisis de la variabilidad observada en las imágenes rupestres plasmadas en emplazamientos y ambientes con diferente potencial para el uso humano (por. ej. tránsito, asentamiento, explotación de recursos asociados) permite evaluar la circulación de personas e información entre espacios sujetos a usos diversos, así como su potencial organización, en términos de articulación y jerarquización diferencial, a partir de su marcación visual (Romero y Re 2014; Barberena et al. 2015a, 2017; Romero Villanueva 2019a, 2021; Romero Villanueva et al. 2020; Rughini et al. 2020).

Por su parte, la discusión de temas temporales o históricos, cuyo desarrollo requiere de segmentaciones cronológicas, contribuye a introducir variación en los patrones espaciales y explorar su profundidad temporal (figura 1). Así, las variaciones observadas en las imágenes rupestres a lo largo del tiempo, permiten conectar esta evidencia con la historia poblacional de una región para identificar los momentos en los cuales se inició y, posteriormente, sistematizó y/o diversificó la producción rupestre, así como distinguir cambios y continuidades en los pulsos y ritmos de producción (sensu Fiore 2006) de estas imágenes en distintas escalas espaciales (Romero Villanueva 2019a y b, 2021). Desde luego, la contextualización temporal del arte rupestre constituye un enorme desafío dado que rara vez las imágenes se encuentran cubiertas por sedimento o compuestas por materiales datables en forma cronométrica. No obstante, en el caso la LBB, en estos años se han desarrollado diversas metodologías y aplicado variadas técnicas analíticas que permitieron integrar múltiples tipos de indicadores cronológicos -relativos y absolutos-para ahondar en estas cuestiones (Romero y Re 2014; Barberena et al. 2015a, 2017; Romero Villanueva y Barberena 2015, 2017; Romero Villanueva 2019a y b, 2021; Rughini et al. 2020; Romero Villanueva et al. 2021a, b y c).

Por último, la vinculación del arte rupestre con las tendencias paleodemográficas y paleoclimáticas disponibles permite discutir temas sociodemográficos que contribuyen a abordar 


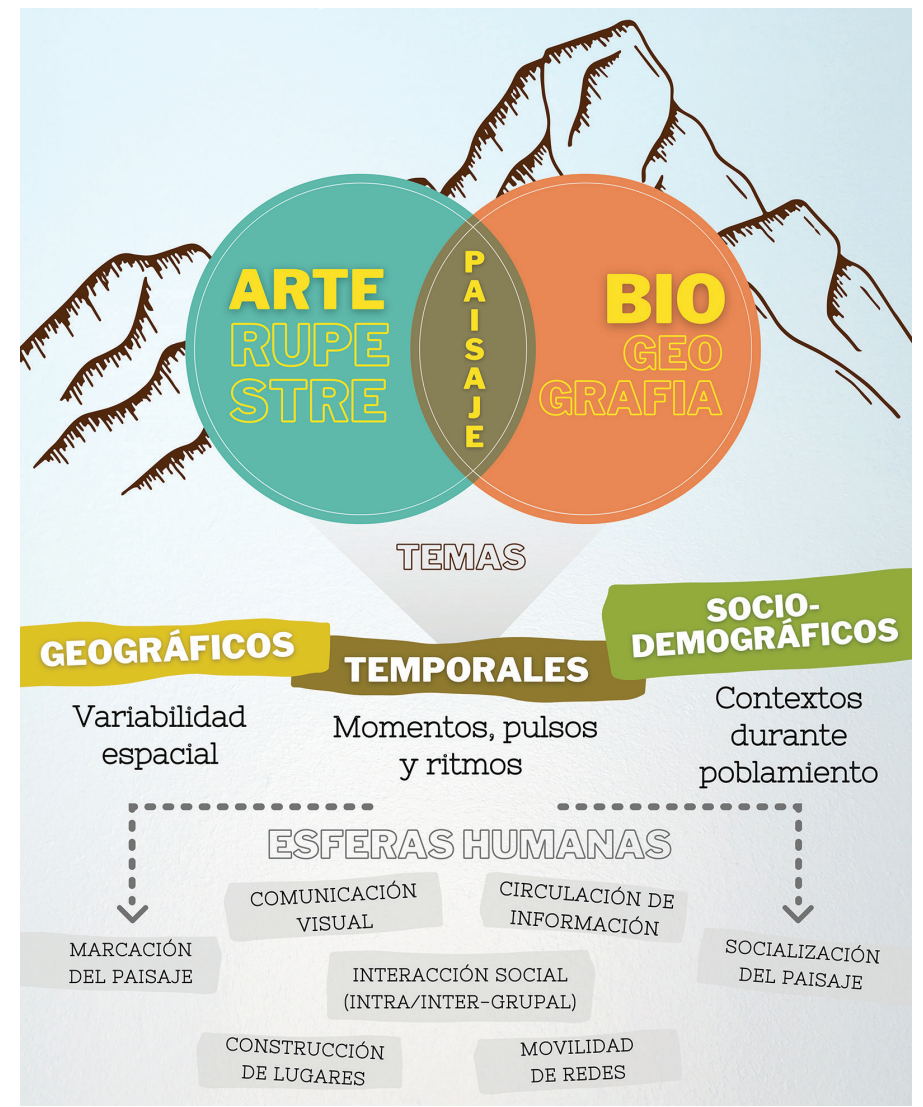

Figura 1. Síntesis esquemática de los principales componentes analíticos y temas de interés a la perspectiva biogeográfica propuesta para un análisis arqueológico multiescalar del arte rupestre

los aspectos sociales y espaciales de la demografía, en conjunto con su dimensión biológica o ecológica (figura 1). Así, en tanto correlato material de códigos visuales y redes sociales que mediaron la interacción de distintos grupos entre sí y con el paisaje que habitaron, esta evaluación posibilita abordar dinámicas humanas complejas vinculadas con la señalización de identidades en el paisaje, la demarcación de territorios y la construcción de lugares y su socialización en una escala arqueológica (Conkey 1984, 1997; Schlanger 1992; Taçon 1994; Domingo Sánz et al. 2008; McDonald 2008; Langley 2013; McDonald y Veth 2006, 2012; Fiore y Acevedo 2018; Haas y Kuhn 2019; Romero Villanueva 2021; entre otros).

En suma, varias razones permiten proponer a la biogeografía humana como un marco de trabajo particularmente apropiado para un estudio sistemático multiescalar del arte rupestre. Por un lado, el paisaje ${ }^{2}$ lato sensu desempeña un rol articulador clave que otorga un carácter analítico fundamental a estas imágenes espacialmente fijas y a los lugares lato sensu en los cuales se ejecutaron. Por el otro, el abordaje multiescalar (por ej. motivo, panel, sitio, región, macrorregión) puede ser operativizado desde una aproximación distribucional y comparativa. Además de factible, esto es deseable en el caso del arte rupestre para explorar el potencial comunicativo multiescalar de estas imágenes, que puede variar de acuerdo con la escala espacial considerada, entre otros factores. Además, la articulación del arte rupestre con las tendencias paleodemográficas y paleoclimáticas disponibles permite evaluar los roles desempeñados por estas imágenes en los diferentes contextos sociodemográficos que suelen caracterizar las dinámicas poblacionales (ver 
Relaciones de la Sociedad Argentina de Antropología 46 (2), julio-diciembre 2021: 595-628

Borrero 1989-90, 1994-95 para la Patagonia; ver Aschero 2000 y Fiore 2006 para expectativas rupestres). Todas estas potencialidades del enfoque aquí propuesto serán retomadas en la discusión.

Claves teóricas: enfoque socioecológico y articulaciones con propuestas complementarias como los estudios de Espacios Internodales y la Geografía Social

De modo general, la propuesta presentada se basa en una perspectiva socioecológica que parte del supuesto de que los individuos y las poblaciones perciben su ambiente -que incluye aspectos ecológicos y sociales- de distintos modos y, sobre la base de esa información, toman decisiones que generan consecuencias materiales (Jochim 1981; Gamble 1990; Minnegal 1995; entre otros). Estas últimas pueden evaluarse arqueológicamente en distintas escalas y mediante diversos indicadores.

En la arqueología de Patagonia, la biogeografía - definida y practicada de diversas maneras- ha sido mayormente empleada en relación con la Ecología Evolutiva (Borrero 1989-90, 1994-95; Barberena 2008, 2013; Neme y Gil 2008; Prates 2008; Goñi 2010; Scheinsohn 2011; entre otros). Este marco sostiene que el ambiente genera constreñimientos y oportunidades para los grupos humanos, quienes tenderán a adoptar estrategias que conlleven la maximización de los beneficios y la minimización de los riesgos y la incertidumbre (Jochim 1981; Halstead y O'Shea 1989; Winterhalder y Smith 1991; Kelly 1995; entre otros). Se entiende por riesgo la variación impredecible de alguna variable ecológica, mientras que la incertidumbre alude a la falta de información acerca de dichas fluctuaciones.

Algunos principios y modelos de la Ecología Evolutiva han sido aplicados desde la Ecología del Comportamiento del Humano, que busca explicar la diversidad conductual en relación con las respuestas ambientalmente contingentes exhibidas por los individuos en su intento de maximizar sus beneficios, concebidas como componentes de estrategias diseñadas para resolver problemas (Winterhalder y Smith 2000; Bird y O'Connell 2006).

Sin embargo, se reconoce que no todas las decisiones humanas son necesariamente óptimas en términos económicos ya que existe la posibilidad de comportamientos que no se rijan por este principio (Richerson y Boyd 2005). Esto permite evaluar la influencia que ejercen, entre otros factores, los contextos demográficos, culturales e históricos particulares sobre las estrategias desplegadas por un grupo humano en un determinado momento (Kelly 1995; Binford 2001; Veth 2005; entre otros).

Respecto del arte rupestre en particular, desde enfoques ecológicos y ecológicos-evolutivos se ha resaltado su potencial como medio material de comunicación visual orientado a la circulación de información para lograr la adaptación, destacando así su relevancia para comprender las dinámicas espaciales y trayectorias históricas adoptadas por los grupos humanos (Conkey 1978; Jochim 1983; Hartley 1992; Barton et al. 1994; David y Lourandos 1998; Fiore 2006; Troncoso 2006; McDonald 2008; McDonald y Veth 2006, 2011, 2012; Re 2010; Scheinsohn 2011; entre otros). La mayoría de estas propuestas se basan en los postulados de Wobst (1977) y Wiessner (1983), quienes analizan el rol del uso de imágenes sobre bienes materiales para la comunicación humana a partir del concepto estilo. Sobre esta base, el arte rupestre fue conceptualizado como un mecanismo para la regulación de la circulación de información intra e intergrupal y el establecimiento de redes de interacción y alianzas a grandes escalas espaciales. Entre los principales aportes del estudio de los usos del arte rupestre desde una postura ecológica se cuentan el énfasis en el análisis de la variabilidad en escala amplia (regional, macrorregional), así como la idea de que desempeña un rol activo en la definición de relaciones y el establecimiento de redes sociales, por ejemplo, al señalar cuestiones relativas a la identidad y/o demarcaciones territoriales (ver detalles en Whitley 2001; Fiore y Podestá 2006; Fiore 2009; McDonald y Veth 2012). Cabe aclarar 
que la codificación de información en el marco de procesos comunicativos vía arte rupestre se canalizaría -principalmente- a partir de las características formales de las imágenes (Troncoso 2006; Fiore 2009; Acevedo y Fiore 2020; entre otros). Así, la recurrencia de semejanzas formales $-\mathrm{y}$, principalmente, morfológicas- permite inferir la existencia de pautas socioculturales que sustentan códigos visuales, necesarios para que la comunicación sea efectiva.

Asimismo, en determinadas escalas e instancias de análisis, la perspectiva biogeográfica propuesta es articulada con otros marcos como los estudios de Espacios Internodales (Nielsen 2006, 2017; Nielsen et al. 2019), generados inicialmente desde la Teoría de la práctica, y la perspectiva de la Geografía Social (sensu Conkey 1984 a partir de la Geografía Cultural sensu Binford 1982), enmarcada originalmente dentro de la arqueología procesual (ver también Borrero 2013). Estas articulaciones tienen por objeto construir un marco analítico de referencia propio que resulte útil y operativo para un análisis arqueológico sobre procesos vinculados con la circulación de información y la marcación visual del paisaje mediante el estudio del arte rupestre de grupos móviles del noroeste de Patagonia (Barberena et al. 2017; Romero Villanueva 2019a; Romero Villanueva y Barberena 2021). Se entiende que la asimilación crítica de los aportes de estos distintos marcos de trabajo contribuye a ampliar y robustecer el alcance conceptual de la presente propuesta.

Los estudios de Espacios Internodales han contribuido a jerarquizar el rol de determinadas zonas - generalmente desérticas, amplias y ubicadas entre nodos poblacionales-en las trayectorias históricas humanas en el largo plazo (Barberena et al. 2017). Así, enfatizan el estudio de "espacios intermedios con respecto a asentamientos relativamente permanentes (escala intrarregional) o regiones con densidades altas de población estable (escala interregional)" (Nielsen 2006:34). El enfoque tiene la virtud de dirigir la atención hacia sectores del espacio que predisponen un uso humano intermitente y, por ende, en un registro arqueológico de baja densidad, aunque éste pueda estar fuertemente concentrado en determinadas localizaciones. En forma exploratoria, propusimos que los espacios estacionales de altura (>2.000 m s.n.m.) del noroeste de Patagonia, en función de sus características biogeográficas y en comparación con espacios circundantes, pudieron haber funcionado como internodos en determinados momentos del pasado (Barberena et al. 2017; Romero Villanueva et al. 2020). Por ello, conllevan el potencial de haber sido utilizados por grupos humanos diferentes asentados en forma más permanente a ambos lados de los Andes. Así, estos espacios son considerados verdaderos 'laboratorios' para explorar dinámicas espaciales y visuales de circulación de información, de diverso tipo y con diferentes fines, materializadas en el arte rupestre (Romero Villanueva y Barberena 2021).

La Geografía Social constituye una propuesta interpretativa para referir al proceso activo y dinámico que, no solo concierne a las pautas de distribución de grupos móviles en el espacio y los lazos que los vinculan, sino también al conocimiento (Rockman 2003; Borrero 2011) que estos grupos tienen de dichos patrones y de su potencial para presentar correlatos materiales (Conkey 1984, 1997). Este conocimiento es valorado como un recurso en sí mismo, aun si es incompleto y/o se encuentra diferencialmente distribuido al interior de un grupo. Este último aspecto es central a la presente propuesta ya que aboga por un reconocimiento activo de los individuos de la geografía social en la cual están inmersos y contribuyen a reproducir. Además, jerarquiza el rol de la circulación de información para el desarrollo de un grupo humano. Por ello, en el marco de esta propuesta, se busca caracterizar el contexto socioespacial en que el arte rupestre fue producido y utilizado. Se entiende que este contexto no representa solo el escenario para el surgimiento y posterior sistematización y/o diversificación de marcaciones visuales en el paisaje, sino que es un elemento activo de su constitución (Conkey 1984, 1997; Hartley 1992; Layton 1992; David y Lourandos 1998; Aschero 2000; Fiore 2006; Troncoso 2006; McDonald y Veth 2006, 2011, 2013; Fiore y Acevedo 2018; entre otros). Por ello, cambios en la geografía social de los grupos bajo estudio pueden, a su vez, haber fomentado o desalentado cambios en 
las estrategias de comunicación visual y circulación de diversos tipos de información, entre otras modificaciones conductuales y organizativas ${ }^{3}$.

Puntos de partida para la generación de objetivos, hipótesis y expectativas rupestres multiescalares: el rol clave de los modelos biogeográficos

El uso de modelos analíticos formales resultó de gran utilidad a la presente propuesta al posibilitar la generación de predicciones acerca del comportamiento humano pasado, en particular, en relación con las dinámicas de comunicación visual de información, interacción social y marcación del paisaje mediante arte rupestre (Romero Villanueva 2019a). Estas predicciones luego fueron contrastadas con la realidad empírica (registro arqueológico) en distintas escalas espaciales. Más específicamente, los modelos biogeográficos de poblamiento humano de la Patagonia de Borrero (1989-90, 1994-95) y del norte del Neuquén de Barberena (2008, 2013) resultaron puntos de partida fundamentales para delinear los objetivos, elaborar las hipótesis y derivar las implicancias observacionales que guiaron la investigación de estas problemáticas en la LBB, donde se aplicó la propuesta en forma pionera. Además, también se tuvieron en cuenta los aportes de otros colegas desde enfoques similares (Neme y Gil 2008; Prates 2008; Goñi 2010; Scheinsohn 2011; Berón et al. 2017; Martínez 2017; entre otros).

El modelo de poblamiento humano de la Patagonia de Borrero (1989-90, 1994-95) plantea que este proceso de dispersión multidireccional se entramó a partir de una jerarquización de los espacios disponibles para ser habitados, lo cual condicionó las historias de ocupación de diversos ambientes y le otorgó un carácter discontinuo a nivel espacial y temporal. Así, la ocupación de un espacio no es concebida como un proceso lineal y, menos aún, irreversible. Este autor propone tres instancias de ocupación del espacio -exploración, colonización, ocupación efectiva- caracterizadas por diferentes modos de interacción entre los humanos y el ambiente físico y social que ocupan, sobre la base de un conocimiento variable de sus propiedades (Borrero 1989-90, 1994-95). A nivel teórico, cada instancia se caracteriza por presentar una firma arqueológica particular, ya que involucra cambios significativos en las estrategias de movilidad y asentamiento, redundancia ocupacional, redes de interacción social y definición de territorios en contextos sociodemográficos distintos. Dados los lineamientos expuestos arriba, es esperable que estos contextos hayan influido en la dinámica de circulación de información y, en particular, en las estrategias de comunicación visual mediante arte rupestre. Por lo tanto, se considera probable observar diferencias en los correlatos materiales asociados a la producción y uso de imágenes fijas de una región de estudio a lo largo de su historia poblacional (Aschero 1988, 1997, 2000; Fiore 2006, 2009; Carden 2008; Re 2010; Scheinsohn 2011; Romero Villanueva 2019a; entre otros).

En particular, en una instancia de ocupación efectiva, cuando se asume que gran parte del espacio deseable es ocupado de forma estable y redundante por diferentes grupos humanos, es esperable que se desplieguen rangos de acción más pequeños y circunscriptos en simultáneo con redes sociales amplias (Borrero 1989-90, 1994-95). También se prevé la aparición de mecanismos dependientes de la densidad, incluyendo aquellos conocidos etnográficamente por ordenar el uso del espacio como el comportamiento territorial, la fusión/fisión de grupos o las actividades rituales (Borrero 1994-95; David y Lourandos 1998; McDonald y Veth 2006; entre otros). Si bien resulta complejo evaluar la existencia de estos mecanismos, el estudio de la comunicación visual mediante arte rupestre desde el enfoque aquí propuesto puede constituir una vía adecuada para su exploración. Así, la posibilidad de que estas imágenes conlleven un valor adaptativo para los grupos humanos, en tanto medio para comunicar parte de la información necesaria para lidiar con el ambiente físico y social (por ej. reforzar lazos sociales, demarcar territorios), las convierte en indicadores potencialmente sensibles para abordar aspectos sociales de la demografía. 
Por su parte, Barberena (2013) plantea un modelo biogeográfico de base actualística para el norte del Neuquén, con énfasis en el Holoceno tardío. El autor segmentó esta zona en términos de la capacidad de carga de herbívoros, las restricciones topográficas y la estacionalidad. Desde su planteo original, el modelo luego fue revisado y ampliado para integrar nuevas variables e indicadores articulados a partir de Sistemas de Información Geográfica (en adelante SIG). Esto permitió estimar el impacto de la estacionalidad, variable que incide en forma clave en la distribución y accesibilidad anual de recursos críticos para la subsistencia humana en el norte neuquino (Barberena et al. 2017; Rughini et al. 2020).

Sobre esta base, se estratificó el paisaje en unidades espaciales significativas al enfoque biogeográfico marco (ver más adelante EJEMPLO DE APLICACIÓN). Se sugirió que las propiedades de estos espacios habrían impactado en las características de las ocupaciones humanas, en particular durante una instancia de ocupación efectiva (sensu Borrero 1989-90), contribuyendo a su jerarquización diferencial en las redes de interacción, circulación y asentamiento humano del noroeste de Patagonia (Barberena 2013; Barberena et al. 2017; Romero Villanueva 2019a; Rughini et al. 2020).

Asimismo, las expectativas generadas por otros autores sobre las condiciones bajo las cuales se inició y posteriormente desarrolló la producción de arte rupestre en Patagonia también contribuyeron a delinear las preguntas de investigación que guían esta propuesta. En particular, ayudaron a definir implicancias observacionales relevantes en términos rupestres (Aschero 1988, 1997, 2000; Fiore 2006, 2009; Carden 2008; Re 2010; Scheinsohn 2011; entre otros). Así, ante una fase de colonización, dada una mayor estabilidad en el uso de determinados espacios funcionalmente complementarios y sus recursos asociados, se ha sugerido que el arte rupestre podría reflejar la construcción de vínculos a mayor largo plazo con el entorno (Fiore 2006). De esta manera, es probable que la producción de imágenes fijas en determinados espacios se inicie durante esta etapa, en la cual hay un retorno previsto (sensu Aschero 2000) a sitios ubicados en diferentes ambientes por parte de grupos de mayor tamaño, que comienzan a ser ocupados en forma redundante a partir de su articulación mediante circuitos de movilidad. A su vez, un aumento demográfico paulatino proveería la suficiente masa crítica (sensu Fiore 2006:51) necesaria para sostener la producción de arte rupestre en el tiempo.

\section{BREVES LINEAMIENTOS METODOLÓGICOS PARA EL ESTUDIO SISTEMÁTICO MULTIESCALAR DEL ARTE RUPESTRE}

La adopción de una perspectiva biogeográfica incentiva la integración de las imágenes rupestres con las demás líneas de evidencia arqueológica documentadas en una región y con el paisaje -actual y pretérito- en el cual se emplazan. Para ello, resulta fundamental generar datos rupestres sistemáticos, proceso que se inicia desde su registro en campo y continúa en laboratorio, donde se procede a su caracterización, contextualización, análisis y discusión (ver detalles en Romero Villanueva 2019a). A continuación, se mencionan sucintamente los principales elementos y estrategias metodológicas empleados para tal fin. La presentación exhaustiva de las unidades, variables, criterios y métodos utilizados se realizará en otro trabajo en curso que complementa los lineamientos conceptuales del enfoque publicados en este.

\section{Perspectiva espacial multiescalar de base distribucional y comparativa}

El énfasis distribucional de la presente propuesta, dada su base biogeográfica, implica concebir el registro arqueológico como un fenómeno espacialmente continuo, en el cual el artefacto -o 
motivo rupestre sensu Aschero (1988)-es la unidad de análisis (ver detalles y citas de antecedentes de esta perspectiva en el norte del Neuquén en Rughini et al. 2020). Esto permite visualizar en un marco espacial continuo diferentes evidencias arqueológicas (por ej. lítico, cerámica, motivos rupestres) y analizar de forma comparativa su composición, densidad y distribución en el paisaje dentro de un marco de referencia común. La articulación de datos de distintas líneas de evidencia se desarrolla mediante análisis estadísticos, mapas y modelos elaborados a partir de SIG. Esta última herramienta es considerada como una tecnología integradora que favorece la interacción, comprensión y visualización de información espacial. En línea con objetivos biogeográficos, es una herramienta metodológica fundamental para combinar diversas fuentes de datos (por ej. ecológicos, geológicos, geográficos y arqueológicos) y reconstruir la estructura del paisaje (Barberena et al. 2017; Romero Villanueva et al. 2020; Rughini et al. 2020).

Sobre esta base distribucional, la propuesta adopta una perspectiva multiescalar que entiende las diferentes escalas en términos jerárquicos e inclusivos (sensu Delcourt y Delcourt 1988). Así, su articulación permite un análisis progresivo de los resultados al avanzar desde áreas pequeñas -con información de alta resolución espacial y temporal- hacia otras más amplias que, a pesar de la pérdida de resolución, permiten visualizar patrones humanos que se expresan en extensiones espaciales y temporales mayores. Este cambio estratégico de escalas permite amalgamar la perspectiva distribucional con la necesidad operativa de definir distintos niveles escalares (arbitrarios) para el abordaje arqueológico de procesos socioecológicos continuos (Bailey 1983; Delcourt y Delcourt 1988).

La perspectiva multiescalar referida resulta particularmente apropiada para el estudio de motivos rupestres por su potencial de transmitir variados tipos de información según la escala. Dada la mirada conceptual que estructura la propuesta, la mayor parte del análisis se realiza en una escala regional (sensu Dincauze 2000). En el caso de aplicación utilizado aquí como ejemplo, corresponde espacialmente con la LBB e incluye los diferentes sectores biogeográficos identificados en su interior (ver más adelante figura 2). Además, se emplea una escala macrorregional (sensu Dincauze 2000) que contempla la LBB, ubicada en el norte del Neuquén, en conjunto con otras regiones del noroeste de Patagonia y áreas cercanas en ambas vertientes de los Andes. Asimismo, se utilizan escalas espaciales más pequeñas. La escala microrregional o local (sensu Dincauze 2000) remite a espacios acotados del área de estudio, operativamente definidos como sitios y localidades (ver detalles en Romero Villanueva 2019a, 2021 y Rughini et al. 2020). Por otra parte, las escalas del soporte y del motivo representan las menores extensiones espaciales de relevancia a las preguntas de interés (Romero Villanueva 2019a). Como se desarrollará en la discusión, el estudio del arte rupestre desde la perspectiva multiescalar propuesta permitió abordar temas variados en las escalas consideradas operativas para abordar la expresión multiescalar de los procesos bajo estudio relativos a la comunicación visual, la circulación de información y la interacción social intra e intergrupal (por. ej. escala sitio: marcación visual de lugares persistentes; escala regional: jerarquización visual de espacios con usos diferenciales, pero complementarios; escala macrorregional: redes de información e interacción social intergrupal).

Perspectiva holística multidimensional: análisis integral de aspectos formales, arqueométricos y contextuales del arte rupestre

Sumado a la perspectiva multiescalar, esta propuesta también implementa una perspectiva holística multidimensional para el estudio del arte rupestre que enfatiza tres dimensiones de análisis complementarias: la formal, la arqueométrica y la contextual (Romero Villanueva 2019a). A los fines expositivos, a continuación se presenta brevemente cada dimensión por separado a pesar de que las tres están interconectadas en las imágenes bajo estudio, aspecto que enfatiza la presente 
propuesta. Desde luego, la cantidad de datos disponibles para cada dimensión puede variar ya que las afectan factores diversos (por ej. muestra, preservación, etapa de la investigación, fondos disponibles para análisis). No obstante, la propuesta prevé esta situación, ya que el uso de unidades analíticas y variables con estados específicos ${ }^{4}$ definidos en forma previa permite una adecuada articulación de nueva información a medida que está disponible (Romero Villanueva 2016, 2019a). La integración de información se sustenta en el modelo de análisis e interpretación arqueológica de fibras y cables (sensu Wylie 2002), donde la imbricación de las múltiples dimensiones consideradas, permite generar mayor fortaleza y factibilidad a las proposiciones interpretativas. Así, esta integración holística multidimensional permite un mayor acercamiento a la complejidad real de los procesos subyacentes a las prácticas humanas en las que las imágenes rupestres fueron pensadas, producidas y utilizadas.

Brevemente, la dimensión formal de análisis implica el estudio de las imágenes en sí mismas y de sus soportes, y de las relaciones que presentan entre sí (sensu Taçon y Chippindale 1998). Para ello, el primer paso consiste en identificar y, posteriormente, clasificar las unidades visuales que componen un conjunto de imágenes rupestres, lo que en ocasiones culmina en la elaboración de una tipología (Romero Villanueva 2016, 2019a). Se opta por utilizar los motivos y los elementos como las unidades de análisis básicas que componen las imágenes bajo estudio. La caracterización de los motivos y sus elementos puede contemplar múltiples y variadas propiedades formales básicas entre las que se enfatizan la morfología y la técnica, además de otras relevantes a la muestra bajo estudio (por ej. colores y grados de desvaído de pinturas o pátinas de grabados).

A su vez, la dimensión arqueométrica se orienta a generar datos independientes pero complementarios sobre el arte rupestre que permitan ahondar en las tendencias ya identificadas, o bien, visualizar nuevas (Romero Villanueva 2019a, Romero Villanueva et al. 2021c). Se aplican técnicas físico-químicas de análisis (por ej. Microscopía, RAMAN, SEM-EDS) para profundizar en diversos aspectos de los motivos rupestres (composicionales, técnicos, visuales, de inversión laboral, temporales) que conllevan el potencial de revelar información -intencional o no intencional-sobre las prácticas involucradas en la producción rupestre y sus implicancias en términos de movilidad, territorialidad y organización espacial humana, entre otros aspectos (Fiore 2009; Sepúlveda 2009, 2020; MacDonald et al. 2019, 2020; entre otros). De forma excepcional, como en el caso de aplicación utilizado aquí como ejemplo, esta información resultó un insumo fundamental para avanzar en la generación de cronologías cronométricas (Romero Villanueva et al. 2021b).

Por último, la dimensión contextual, que es la más inclusiva, abarca el estudio del arte rupestre en relación con diversos aspectos de la misma evidencia y de otras evidencias e indicadores arqueológicos en distintas escalas espaciales y temporales, que conllevan diferente resolución conductual. Esto permite dar cuenta del amplio espectro de decisiones tomadas por los ejecutantes de las imágenes consideradas, ya sean acciones individuales y/o sociales más o menos conscientes, pero que, al estar cultural y/o social y/o económicamente informadas, pueden echar luz sobre los roles desempeñados por el arte rupestre (Conkey 1984, 1997; Aschero 1988, 1997, 2000; Hartley 1992; David y Lourandos 1998; McDonald y Veth 2006, 2011, 2012; Carden 2008; Fiore 2009; Re 2010; entre otros). En el caso particular bajo estudio, esta dimensión implicó analizar la producción y el uso de imágenes rupestres en relación con su ubicación espacio-temporal y contexto en diferentes escalas (sitio, región, macrorregión), a partir de distintas variables para el nivel de las imágenes, los soportes y los sitios, y de su relación con otras líneas de evidencia arqueológica, los modelos biogeográficos de poblamiento y con la información paleodemográfica y paleoambiental disponible (Romero Villanueva 2019a, 2021). Este análisis permitió el desarrollo de posteriores interpretaciones sobre las estrategias de circulación de información e interacción social mediante comunicación visual implementadas por los grupos humanos en distintas escalas espaciales y a lo largo del poblamiento de la región. 


\section{EJEMPLO DE APLICACIÓN: LA LOCALIDAD BARRANCAS-BUTA RANQUIL (NORTE DEL NEUQUÉN, PATAGONIA)}

\section{Marco regional y segmentación biogeográfica}

La propuesta aquí presentada fue aplicada en forma pionera al estudio del arte rupestre de la LBB, ubicada en el norte de la provincia del Neuquén $\left(36^{\circ}\right.$ a $37^{\circ}$ Latitud Sur, noroeste de Patagonia, Argentina) (figura 2). Esta región de cerca de $1.200 \mathrm{~km}^{2}$ presenta marcadas diferencias topográficas, climáticas y ecológicas en un espacio acotado (aproximadamente $30 \mathrm{~km}$ oeste-este). En términos biogeográficos, ofrece una excelente oportunidad para estudiar cómo varían los procesos de circulación de información en relación con las formas de organización espacial humana en espacios heterogéneos. Asimismo, dado que la LBB abarca una parte importante de la variación topográfica y ecológica presente en la escala más amplia del noroeste de Patagonia (Oyarzábal et al. 2018), las observaciones regionales tienen implicancias relevantes en escala macrorregional. Así, algunas discusiones implican comparar el registro de la LBB con lo documentado por otros investigadores en diversas regiones de ambas vertientes de los Andes (figura 2) (Romero Villanueva 2019a; Romero Villanueva et al. 2020, 2021d).

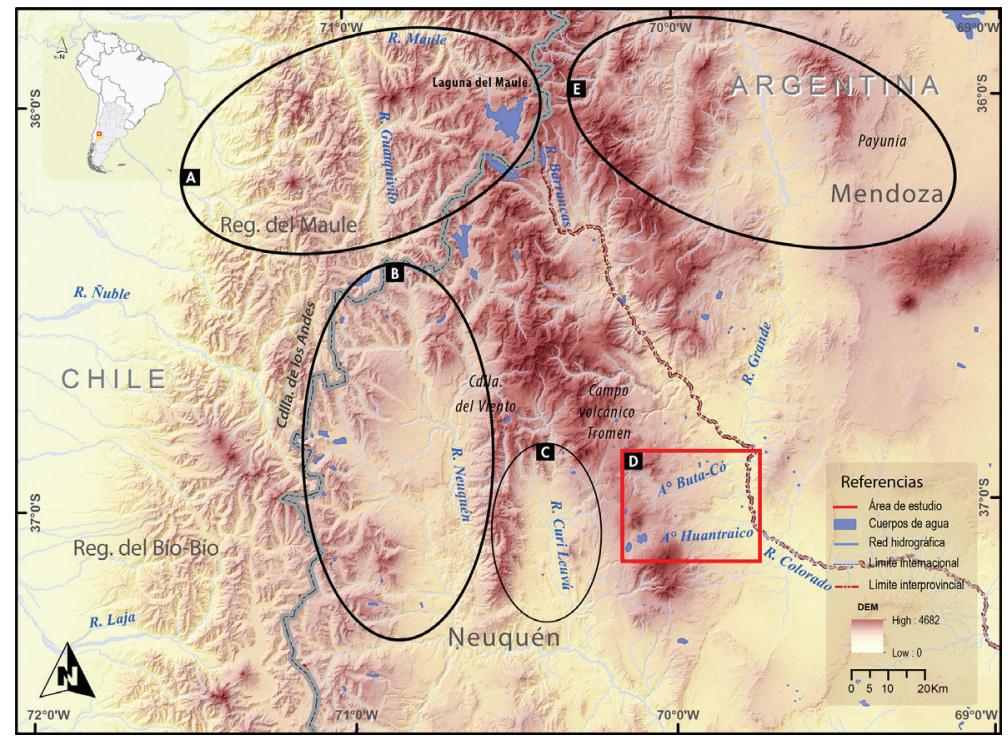

Figura 2. Ubicación del área de estudio, la LBB (recuadro), y de otras áreas con arte rupestre del noroeste de Patagonia consideradas en escala macrorregional (óvalos). Referencias de las áreas (cobertura aproximada): A: región cordillerana del Maule (Chile); B: cuenca superior-media del río Neuquén (Argentina); C: cuenca del río Curi Leuvú (Argentina); D: LBB y E: sur de la provincia de Mendoza

(Argentina). Referencias del mapa: R.: Río; A: Arroyo; Reg.: Región y Cdlla.: Cordillera

El rango altitudinal observado en la LBB (850 a 2.200 m s.n.m.) abarca las provincias fitogeográficas del Monte, Patagónica y Altoandina (Oyarzábal et al. 2018) (figura 3). En trabajos previos se ha empleado un modelo de capacidad de carga de ovinos para evaluar la capacidad de carga de guanacos, el recurso faunístico más importante en la dieta humana a nivel regional (Barberena 2013). Sobre esta base, la provincia Patagónica puede caracterizarse como de alta capacidad de carga, mientras el Monte presenta sectores de productividad media a baja (Rughini et al. 2020). Sin embargo, la provincia del Monte ofrece recursos vegetales clave como algarrobo 
(Prosopis), molle (Schinus) y chañar (Geoffroea) (Llano 2015), marcando una complementariedad clave entre los recursos alimenticios que ofrecen estas regiones. Esta información fue articulada con un modelo geográfico de estacionalidad construido a partir de la variación en la precipitación total mensual a lo largo del año (ver detalles en Rughini et al. 2020) (figura 3). Así, los espacios de menor altitud de la LBB están disponibles anualmente para la ocupación humana, mientras que aquellos con altitudes desde los 1.800 m s.n.m. presentan una amplia cobertura nívea y marcadas restricciones a la circulación humana durante la estación invernal.

La integración de los patrones descriptos permitió diferenciar tres sectores biogeográficos dentro de la LBB con diverso potencial para el uso, la circulación y el asentamiento humano (figura 3) (Rughini et al. 2020). En particular, para una instancia de ocupación efectiva (sensu Borrero 1989-90), en la cual se asume que existe abundante información con respecto a la configuración del paisaje y los rangos de acción o territorios ya se encuentran establecidos (Eerkens 1999), se propuso que los sectores altos (con elevada capacidad de carga de herbívoros o $k$ ) presentarían ocupaciones más intensas y/o recurrentes que aquellos con baja $k$ (Barberena 2013; Romero y Re 2014). También se sugirió la posible existencia de procesos de competencia social en los primeros que conllevarían una demarcación simbólica del espacio más intensa en comparación con los otros sectores, en función de su mayor productividad.

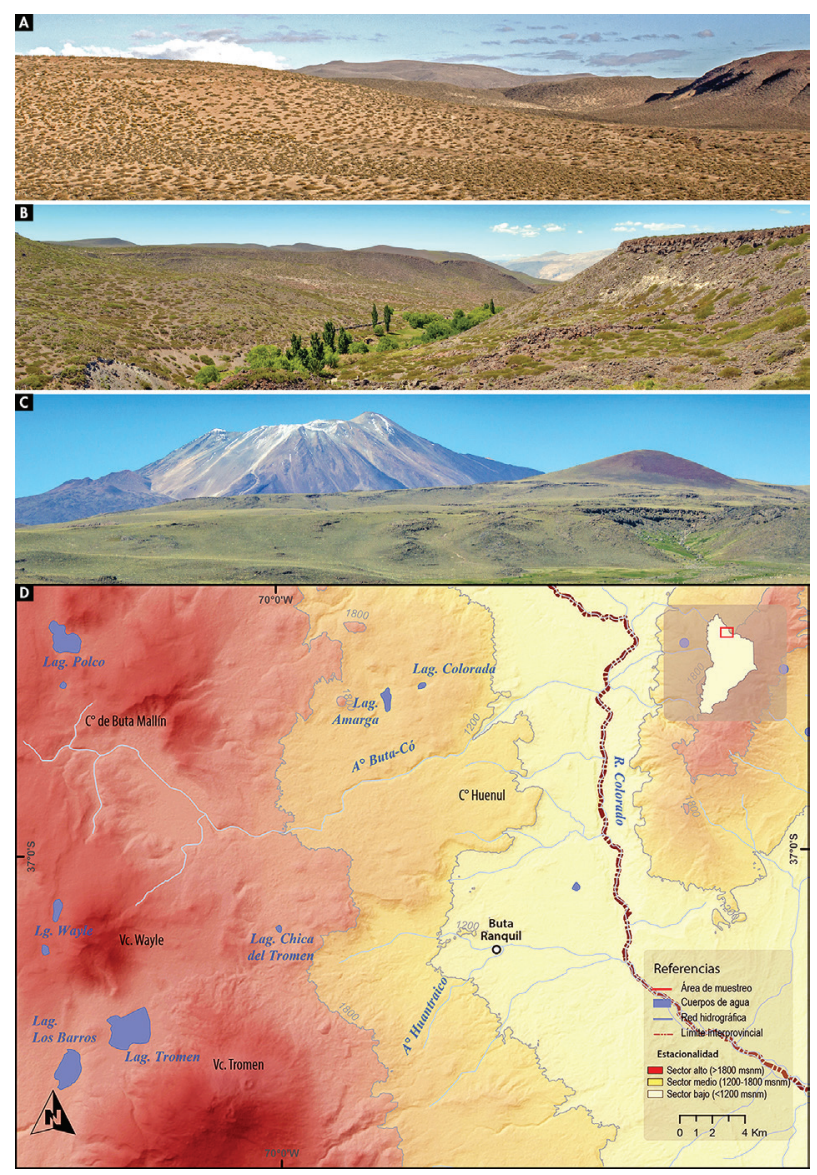

Figura 3. Sectores biogeográficos de la LBB. A: provincia del monte en sectores bajos ( $<1.200 \mathrm{~m}$ s.n.m.);

B: ecotono en sectores intermedios (1.200-1.800 m s.n.m.); C: provincia patagónica en sectores altos (>1.800 m s.n.m.); D: reconstrucción de la estacionalidad regional e indicación de sectores biogeográficos 
Breve reseña de los antecedentes de investigación: características y cronología de las ocupaciones humanas

La información publicada para la LBB, previo al inicio del proyecto que gestó la propuesta analítica aquí presentada, era escasa y se limitaba a breves referencias generales sobre dos sitios con arte rupestre: Cueva Huenul 1 (en adelante $\mathrm{CH} 1)^{5}$ y Paso de las Tropas 4 (en adelante PDT4) (Fernández 1974-76, 1978; Schobinger 1985). En el año 2010 se inició el proyecto arqueológico referido, dirigido por el Dr. Barberena, dentro del cual el estudio del arte rupestre desde un enfoque biogeográfico multiescalar ha ocupado un rol fundamental desde el comienzo (Barberena 2013; Romero y Re 2014 y publicaciones sucesivas del equipo). A la fecha, se han realizado múltiples trabajos de campo que incluyen prospecciones y recolecciones dirigidas de superficie (muestreos y transectas), sondeos, excavaciones y estudios paleoecológicos, además de documentación de arte rupestre. Como resultado, se ha relevado un registro arqueológico abundante y variado generado a partir de conocimiento interdisciplinario. Entre las principales líneas trabajadas se cuentan la tecnología lítica y cerámica, la geoarqueología, la zooarqueología, la arqueobotánica, la paleoecología y el arte rupestre y mobiliar, además del análisis de pigmentos y objetos coloridos (Barberena 2013; Romero y Re 2014; Barberena et al. 2015a y b, 2017; Romero Villanueva y Barberena 2015, 2017; Romero Villanueva 2016, 2019a y b, 2021; Fernández et al. 2017; Llano et al. 2020; Romero Villanueva et al. 2020; Rughini et al. 2020; entre otros).

Por el momento, la información cronométrica disponible para contextualizar temporalmente las ocupaciones humanas de la LBB consiste en un total de veintitrés fechados radiocarbónicos AMS, entre los que se destaca el fechado directo de un soporte de arte mobiliar (Romero Villanueva y Barberena 2017:372) y cuatro motivos rupestres (Romero Villanueva 2019a:161; Romero Villanueva et al. 2021b). Cabe resaltar que, de los dieciocho fechados restantes, todos excepto uno provienen de sitios con arte rupestre (Barberena et al. 2015a:tabla 1; Romero Villanueva 2019a:tabla 6.3; Romero Villanueva et al. 2021a:tabla 1). Sumado a ello, también se dispone de información temporal relativa asociada con evidencias cerámicas, líticas, de arte rupestre y, en forma exploratoria, de hidratación de cortezas de obsidianas (Rughini et al. 2020; Romero Villanueva 2019a, 2021; Romero Villanueva et al. 2021a).

Sobre esta base se sostiene que las ocupaciones humanas en la LBB presentan una señal cronológica que se inicia en el Holoceno temprano (12.000 años cal. AP), con posterioridad a la desaparición de taxa de megafauna -Pilosa- en ambientes de la provincia del Monte, representados en el sitio CH1 (Llano et al. 2020; ver también Barberena et al. 2015a). Estas fechas amplían la profundidad temporal de la presencia humana en esta provincia fitogeográfica, en general, y en el extremo norte del actual territorio de la provincia del Neuquén, en particular. Las bajas frecuencias de materiales sugieren ocupaciones breves con muy escasa intensidad de descarte. Esta señal ocupacional inicial de baja magnitud continúa durante el Holoceno medio (Romero Villanueva 2019a; Llano et al. 2020; Romero Villanueva et al. 2021b; ver también Barberena et al. 2015a). Finalmente, hacia el Holoceno tardío, se registra un incremento en la diversidad y frecuencia de indicadores de presencia humana respecto de momentos previos, aunque se observan intensidades diferenciales de acuerdo con el tipo de ambiente. Mientras sitios como CH1, ubicado en los sectores bajos (provincia del Monte), registra evidencias de baja intensidad de ocupación (Barberena et al. 2015a; Romero Villanueva 2021), otros como Cueva Yagui (en adelante CY), emplazado en los sectores intermedios (ecotono provincias del Monte-Patagónica), presenta evidencias de ocupación más intensas y/o prolongadas durante este lapso (Romero Villanueva et al. 2021a). 


\section{RESULTADOS Y DISCUSIÓN: COMUNICACIÓN VISUAL Y CIRCULACIÓN DE INFORMACIÓN EN PERSPECTIVA MULTIESCALAR}

Hasta el momento, la mayoría de los trabajos de campo sistemáticos en la LBB se han concentrado en torno a dos cursos de agua menores, aunque permanentes, que drenan al río Barrancas: los arroyos Buta Có y Huantraico (figura 3). En esta zona de muestreo sistemático, se implementó un programa de búsqueda dirigida diseñado para identificar específicamente sitios con arte rupestre. Así, se desarrolló una prospección en campo (12 km lineales) luego de haber identificado potenciales soportes rocosos por medio de análisis de imágenes satelitales (Google Earth) en laboratorio. A esto se suman $26,8 \mathrm{~km}$ prospectados mediante transectas, en las cuales no se registraron motivos en los múltiples soportes rocosos disponibles (Romero Villanueva 2019a; Rughini et al. 2020). Estas tareas permitieron generar una superficie de muestreo comparable para los diferentes sectores de la LBB, por lo que las tendencias observadas en ellos son significativas (Romero Villanueva 2019a). Entre otros resultados, se localizaron diez nuevos sitios que se sumaron a los dos ya conocidos en la literatura - $\mathrm{CH} 1$ y PDT4-. Este programa de prospección también evidenció la presencia de soportes disponibles potencialmemte aptos para la ejecución de arte rupestre que no fueron marcados (incluso con similares condiciones de topografía, orientación, presevación, etc.), lo que resalta el carácter deliberado del emplazamiento de las imágenes en sectores discretos del paisaje.

Se relevó un total de 1.128 motivos rupestres, concentrados en doce sitios, que fueron caracterizados a partir de sus aspectos formales, contextuales y, en menor medida, arqueométricos (tabla 1) (Romero Villanueva 2019a; Rughini et al. 2020). Todos ellos fueron pintados, a excepción de dos tridígitos que fueron grabados en los sectores altos. Los motivos se ejecutaron en una amplia variedad de tipos de sitios que incluye cuevas, aleros, paredones a cielo abierto y situaciones mixtas. También se registró variabilidad al nivel de los soportes seleccionados entre los que se incluyen diferentes tipos de rocas (ignimbritas y basaltos) de distintas formaciones. En cuanto a su topografía, en gran medida se utilizaron paredes, si bien hay imágenes en sectores de techo de áreas bajo reparo, así como en bloques.

Tabla 1. Sitios con motivos rupestres en la LBB por sectores biogeográficos

\begin{tabular}{|c|c|c|c|}
\hline Sector biogeográfico & Localidad rupestre & Sitio & N motivos \\
\hline \multirow{9}{*}{$\begin{array}{c}\text { Bajos } \\
(<\mathbf{1 . 2 0 0} \mathrm{m} \text { s.n.m. })\end{array}$} & \begin{tabular}{|c|}
- \\
\end{tabular} & Cueva Huenul 1 & 446 \\
\hline & \multirow{7}{*}{$\begin{array}{l}\text { El Ciénego } \\
\text { (CNG) }\end{array}$} & CNG1 & 65 \\
\hline & & CNG3 & 153 \\
\hline & & CNG4 & 71 \\
\hline & & CNG5 & 2 \\
\hline & & CNG6 & 1 \\
\hline & & CNG7 & 20 \\
\hline & & Subtotal & 312 \\
\hline & \multicolumn{2}{|c|}{ Subtotal } & 758 \\
\hline \multirow{3}{*}{$\begin{array}{c}\text { Intermedios } \\
(1.200-1.800 \text { m s.n.m. })\end{array}$} & \multirow{2}{*}{-} & Cueva Yagui & 180 \\
\hline & & PDT4 & 21 \\
\hline & \multicolumn{2}{|c|}{ Subtotal } & 201 \\
\hline \multirow{5}{*}{$\begin{array}{c}\text { Altos } \\
(>1.800 \text { m s.n.m.) }\end{array}$} & \multirow{4}{*}{$\begin{array}{c}\text { Paso de } \\
\text { las Tropas } \\
\text { (PDT) }\end{array}$} & PDT2-3 & 59 \\
\hline & & PDT5 & 72 \\
\hline & & PDT6 & 38 \\
\hline & & Subtotal & 169 \\
\hline & \multicolumn{2}{|c|}{ Subtotal } & 169 \\
\hline \multicolumn{3}{|c|}{ Total general } & 1128 \\
\hline
\end{tabular}


En términos temporales, el desarrollo de una metodología especialmente diseñada para contextualizar el arte rupestre, que articula información de distinto grano provista por múltiples indicadores cronológicos -principalmente relativos y, en menor medida, absolutos- permitió identificar distintos momentos de ejecución de las imágenes rupestres de la LBB y, posteriormente, asignarles una cronología (Romero Villanueva 2019a, 2021). Se propuso que la mayoría de los motivos de la región fueron ejecutados en diferentes momentos del Holoceno tardío y, en particular, dentro del lapso 1.700 a 300 años cal. AP (Romero Villanueva 2019a, 2021). No obstante, se realizaron análisis pioneros en los estudios del arte rupestre a nivel nacional que, por primera vez para el norte de Patagonia, permitieron fechar en forma directa por AMS cuatro motivos rupestres que sugieren episodios recurrentes, pero separados de pintado entre los 6800 a los 3000 años radiocarbónicos AP, al menos en el sitio CH1 (Romero Villanueva 2019a, 2021; Romero Villanueva et al. 2021b). Aunque en la actualidad no existe evidencia temporal sólida que permita sostener la producción de arte rupestre en la LBB durante el Holoceno temprano, no se descarta esta posibilidad dado que, durante ese lapso, hay evidencias de ocupación asociadas a la exploración del sitio CH1. Además, algunos de los niveles de esos momentos, contienen pigmentos (Romero Villanueva 2019a, 2021).

A continuación, se reseñan brevemente algunos resultados obtenidos a partir del análisis de múltiples dimensiones del arte rupestre de la LBB en diferentes escalas espaciales. Como se adelantó en la introducción, retomaremos discusiones ya iniciadas que son y serán profundizadas en otras publicaciones.

Escala regional: jerarquización visual de un paisaje andino-patagónico sujeto a usos diferenciales pero complementarios

Sobre la base de información etnográfica de uso del espacio y área total ocupada anualmente por diversos grupos humanos (Kelly 2013), en forma exploratoria se ha sugerido que la amplitud espacial de la LBB tiene el potencial de reflejar una fracción importante, aunque indefinida, de los rangos de acción (sensu Foley 1981) de los grupos móviles bajo estudio, pudiendo contener múltiples desplazamientos residenciales entre sus distintos pisos altitudinales (Rughini et al. 2020) (figura 3). En relación con ello, el corpus rupestre regional presenta similitudes y diferencias que permiten echar luz sobre los modos y la intensidad con que fue utilizado y visualmente jerarquizado este espacio.

Por un lado, se evidencian semejanzas formales entre los motivos de la LBB que fueron interpretadas como el correlato material del uso de un código visual común a escala regional (Romero Villanueva 2019a; Rughini et al. 2020) (figura 4). En forma independiente de otros hallazgos, esto sugiere que los sitios con arte rupestre, así como los ambientes en los cuales se emplazan, fueron conocidos y/o utilizados en forma complementaria por los mismos grupos humanos quienes los incorporaron dentro de sus circuitos de movilidad, a los fines de aprovechar los diversos recursos que ofrece cada sector en los distintos momentos del año en que están disponibles (figura 5). Gracias a estos desplazamientos y al uso de un código visual común, la información codificada en el arte rupestre pudo circular en el interior de la LBB a pesar de la fijeza que caracteriza a los motivos (cfr. Aschero 1997; Fiore 2009). Esta forma planificada de uso del espacio regional, mediante la articulación estratégica de ambientes con propiedades contrastantes, habría permitido a los grupos humanos de la región, demográficamente poco densos y móviles, efectuar un uso del espacio eficiente para la ocupación de ambientes desérticos sujetos a estrés temporal como los que caracterizan a la LBB (Romero Villanueva 2019a). 


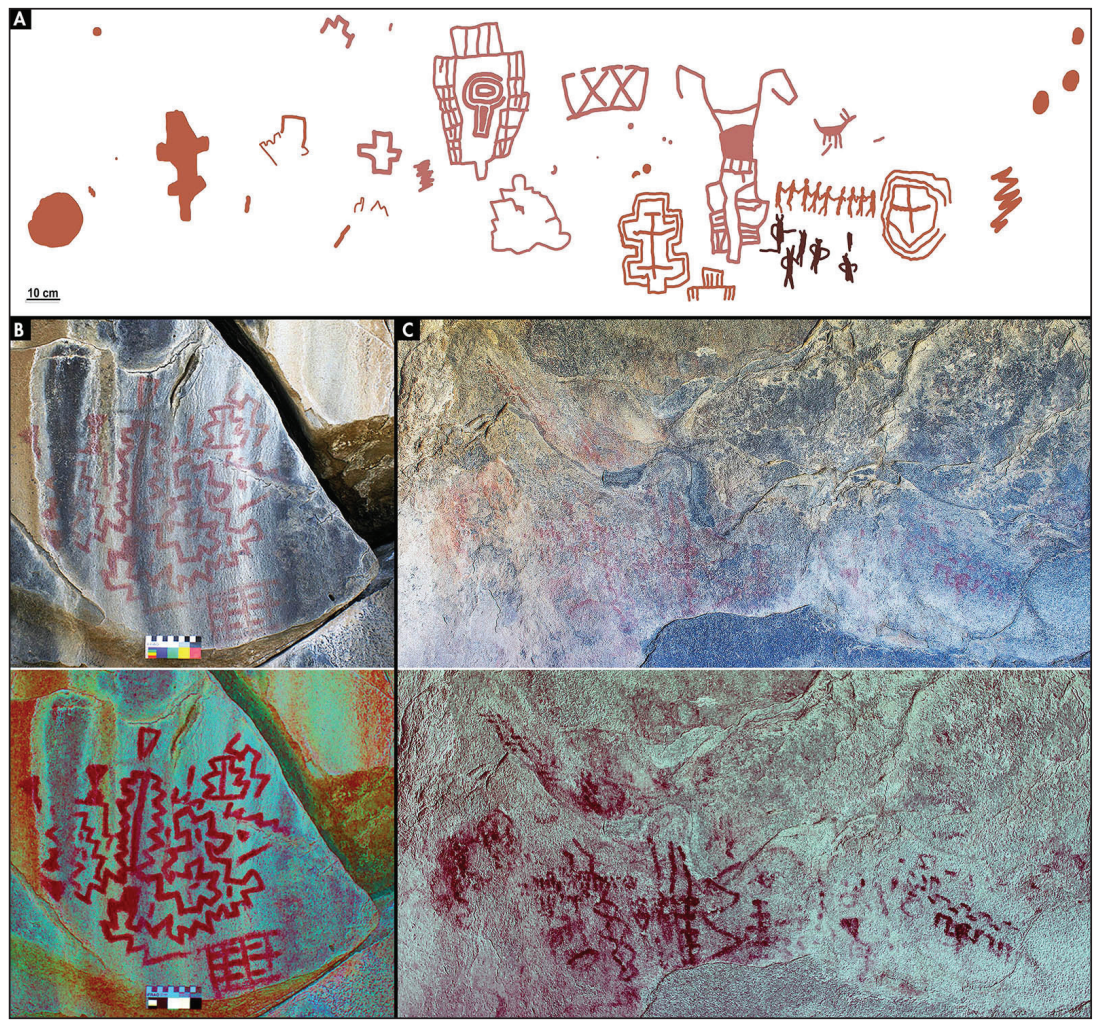

Figura 4. Ejemplos del arte rupestre de la LBB. Referencias: En sectores bajos: A: sitio Cueva Huenul 1 (calco digital) y C: sitio El Ciénego 3 (foto original y resalte digital con DStretch). En sectores intermedios:

B: sitio Paso de las Tropas 4 (foto original y resalte digital con DStretch). DStretch: Harman (2008)

Por otro lado, el análisis de estimación de densidad de Kernel de los motivos rupestres mediante SIG señala una distribución desigual ya que la mayoría de ellos se concentran en los sectores bajos, con una densidad menor en los sectores intermedios y altos (figura 5 y tabla 1) (Romero Villanueva 2019a; Rughini et al. 2020). Cabe aclarar que dos sitios en particular producen los patrones observados al aportar el 55,3\% de la muestra total: $\mathrm{CH} 1$ (446 motivos: 39,5\%) y CY (180 motivos: 15,8\%) ubicados en los espacios bajos e intermedios respectivamente (Romero Villanueva 2021; Romero Villanueva et al. 2021a).

Estos resultados se contraponen con las expectativas iniciales derivadas del modelo marco para esta escala que sugerían una marcación visual comparativamente más intensa en los sectores altos, caracterizados por una mayor capacidad de carga de herbívoros, en función de posible existencia de procesos de competencia social (Barberena 2013; Romero y Re 2014). No obstante, como se verá más adelante, las expectativas generadas desde el modelo sí se cumplen en una escala espacial más amplia o macrorregional, si bien se han propuesto explicaciones alternativas para dicho patrón (Barberena et al. 2017; Romero Villanueva et al. 2020). Así, los resultados rupestres invitan a realizar ajustes en la formulación original del modelo, que contemplaba expectativas de marcación visual similares en escalas espaciales diferentes (Romero Villanueva 2019a).

También se observaron diferencias entre sectores en relación con la presencia/ausencia de algunos tipos de motivos (por ej. los antropomorfos se registran en forma exclusiva en los sectores bajos) y las proporciones de los tipos presentes (por ej. los sectores intermedios presentan una mayor proporción de motivos zoomorfos en comparación con los espacios bajos y altos) (Romero 
Villanueva 2019a; Rughini et al. 2020). En forma exploratoria se sugirió que, en el marco de códigos visuales compartidos a escala regional, estas divergencias podrían vincularse con la señalización de diferentes tipos de información, pertinentes a los usos humanos desplegados en los diversos sectores.

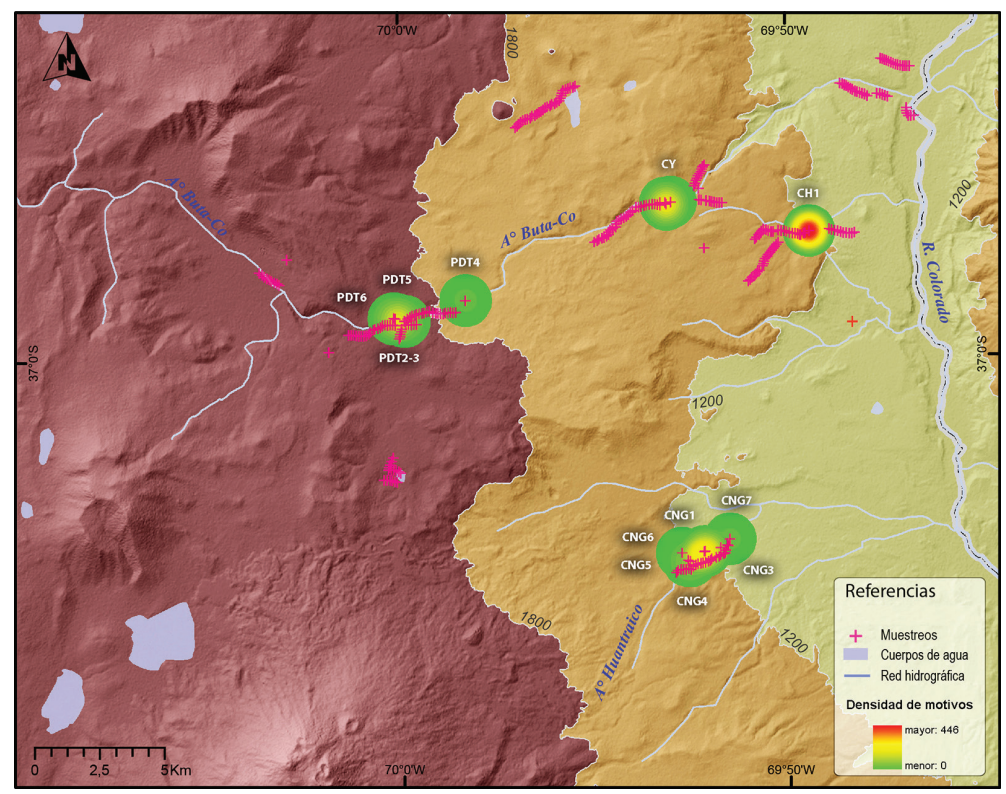

Figura 5. Análisis de estimación de densidad de Kernel mediante SIG de la distribución de motivos rupestres en la LBB. Las cruces indican la ubicación de otros muestreos (superficie y estratigrafía). Referencias: Sectores bajos (color verde o gris claro): Cueva Huenul $1(\mathrm{CH} 1)$ y sitios de la localidad El Ciénego (CNG). Sectores intermedios (color marrón claro o gris intermedio): Cueva Yagui (CY) y Paso de las Tropas 4 (PDT4). Sectores altos (color marrón o gris oscuro): sitios de la localidad Paso de las Tropas (PDT). Tomado de Rughini et al. 2020

En relación con ello, interesa señalar que la estructura espacial del registro de superficie, sumado a diversos proxies de intensidad ocupacional, sugiere una delimitación funcional del espacio dentro de la LBB (Fernández et al. 2017; Rughini et al. 2020; Romero Villanueva et al. 2021a). En particular, esta información indica que los sectores intermedios (1200-1800 m s.n.m.) presentan una frecuencia artefactual -material lítico, cerámico y faunístico-mayor que la registrada en sitios cercanos con excavaciones, ubicados en otros sectores como CH1. En particular, estos indicadores sugieren la realización de actividades vinculadas con estadías prolongadas y/o comúnmente asociadas a espacios de uso residencial. Sobre esta base, se propuso que los sectores intermedios de la LBB habrían funcionado como lugares centrales (sensu Zeanah 2004) desde donde se pudo articular -al menor costo de traslado- el uso del espacio regional en un rango entre los 800-2300 m s.n.m. (Rughini et al. 2020) (figuras 3 y 5). Así, espacios discretos dentro de estos sectores, como CY, serían ocupados en forma potencialmente anual con fines diversos (obtener recursos, procesar vegetales in situ, pintar motivos rupestres), algunos de los cuales pueden tener agendas conflictivas a lo largo del año (Romero Villanueva et al. 2021a).

Entonces, volviendo al arte rupestre, resalta que las dos concentraciones de motivos más grandes de la LBB - $\mathrm{CH} 1$ y CY- se ubican en sectores sujetos a usos humanos diferentes según la demás evidencia arqueológica disponible, lo cual se verifica en sus respectivos registros estratigráficos y de superficie (Barberena et al. 2015a; Rughini et al. 2020; Romero Villanueva 2021; 
Romero Villanueva et al. 2021a). Lejos de representar una contradicción, dada la polivalencia y el potencial del arte rupestre de transmitir tipos de información variada de acuerdo con los contextos de producción y uso de las imágenes, resulta plausible que las diferencias observadas entre sectores reflejen la circulación de tipos de información particulares a cada uno de ellos. Los resultados que se resumen en el siguiente acápite ofrecen datos a escala local, o de sitio, que permiten afinar estas interpretaciones y avanzar en la definición de los potenciales tipos de información transmitidos en diferentes casos de acuerdo al contexto.

Escala de sitio: el rol versátil del arte rupestre en la construcción visual de 'lugares persistentes' dentro de la $L B B$

CH1 y CY -aunque el primero en particular- destacan a nivel regional por haber sido marcados, en forma recurrente, mediante un arte rupestre profuso y variado (figuras 4 y 5 y tabla 1). Esta cualidad ha resultado un insumo clave para complejizar en sus historias de uso (sensu Holdaway y Wandsnider 2006) en tanto aporta información independiente que complementa aquella expresada en el registro estratigráfico (Romero Villanueva 2021; Romero Villanueva et al. 2021a). Así, la indagación sobre las historias ocupacionales particulares que enmarcaron la producción y el uso de estas imágenes puede echar luz sobre los potenciales roles y tipos de información transmitidos en cada caso.

Tomando como ejemplo a CH1, la alta intensidad que caracteriza su producción rupestre contrasta con las tendencias sugeridas por los indicadores estratigráficos (Barberena et al. 2015a; Romero Villanueva 2021). El sitio cuenta con una secuencia de 12.000 años calendáricos caracterizada por una baja intensidad ocupacional ${ }^{6}$ que evidencia distintos episodios breves, pero recurrentes, que se sucedieron en forma discontinua a lo largo de todo el Holoceno, aunque con una mayor frecuencia en momentos tardíos (Barberena et al. 2015a; Llano et al. 2020). En relación con su arte rupestre, la mayoría habría sido ejecutado en diferentes momentos del Holoceno tardío (1700 a 300 años cal. AP), a excepción de cuatro motivos que representan episodios de pintado recurrentes, pero separados durante el Holoceno medio (Romero Villanueva 2021; Romero Villanueva et al. 2021b). Se han observado cambios en la abundancia y propiedades formales de las imágenes asignadas a estos diferentes momentos, así como en sus ritmos de producción e inversión laboral, que sugieren que el arte rupestre desempeñó diversos roles en la historia ocupacional del sitio (Romero Villanueva 2021).

La información disponible actualmente indica que la producción rupestre en $\mathrm{CH} 1$ se inició en el Holoceno medio, en sintonía con una virtual ausencia de registro arqueológico en la estratigrafía y/o superficie del sitio (Barberena et al. 2015a; Romero Villanueva 2021; entre otros). Esto sugiere que las estadías en el sitio (por corto tiempo y/o por poca gente) se centraron en la producción rupestre y, en particular, en la ejecución de motivos homogéneos: peiniformes de color negro (Romero Villanueva 2021). Este modo de usar el sitio y su arte rupestre ocurre en el marco más amplio de notables reorganizaciones conductuales en otros ambientes desérticos de Sudamérica en asociación a un período árido (8000 a 6000 años atrás) (Riris y Arroyo-Kalin 2019; Llano et al. 2020; Timpson et al. 2021). Dado este escenario, consideramos que el emplazamiento de $\mathrm{CH} 1$ en un ambiente de Monte pudo haber influenciado la decisión de utilizar el sitio, y los sectores más áridos de la LBB en general, solo como lugares de paso (sensu Veth 1993, 2005), que pudieron incluso haber sido abandonados por períodos (Rughini et al. 2020).

Al retomar los aportes de autores que han analizado el rol de distintos tipos de información (por. ej. social, religiosa, ecológica, técnica) y su circulación en sociedades de pequeña escala, consideramos probable que la información transmitida en el sitio durante este lapso se haya orientado al establecimiento de conexiones sociales firmes en escala amplia (Conkey 1978, 1984; 
Jochim 1981; Gamble 1982; Layton 1991, 1992; Morphy 1991; Whallon 2006, 2011; Troncoso et al.2016; entre otros). Numerosos estudios etnográficos destacan la importancia de la movilidad de pequeñas partidas de personas en pos de la adquisición y renovación de información, en especial en momentos de estrés ambiental. Ello permite que diferentes grupos forjen lazos que pueden constituir redes de seguridad (sensu Whallon 2006), potencialmente de gran valor adaptativo en ambientes inciertos, al posibilitar ampliar la escala espacial y social de circulación de información sobre lugares, personas y recursos, al tiempo que propician la generación de derechos y obligaciones intergrupales. El establecimiento de estas conexiones pudo ser de vital importancia durante el Holoceno medio, ante el riesgo que revisten cambios climáticos en ambientes con demografía estable o baja (Riris y Arroyo-Kalin 2019; Grasset et al. 2021; Timpson et al. 2021). La reiteración durante milenios del mismo tipo de motivo (peiniformes pintados en negro) con variaciones mínimas (por ej. cantidad, largo proporcional y rectitud de púas, púas con elementos asociados), podría indicar que su ejecución estuvo sujeta a condiciones socioculturales particulares. A los fines de la comunicación visual, al establecer un $\mathrm{Canon}^{7}$, se limita la variabilidad formal (en potencia, ilimitada) (Wobst 1977; Aschero 2000; Fiore 2009; entre otros). Esto tiende a favorecer la aceptación social de una determinada imagen y que la información codificada en ella sea interpretada en forma correcta, aunque esto suceda en forma esporádica y/o por grupos humanos ubicados a distancias sociales variables por fuera del grupo residencial local (Gamble 1982; Aschero 2000; Fiore 2006, 2009; Whallon 2006; Troncoso et al. 2016; entre otros).

Milenios después, durante el Holoceno tardío, la producción rupestre en CH1 se intensifica y diversifica en sintonía con ocupaciones de mayor redundancia y diversidad según la información provista por múltiples indicadores (Barberena et al. 2015a; Romero Villanueva 2021; entre otros). Estas evidencias sugieren la realización de múltiples actividades, algunas de ellas vinculadas con tareas de caza, recolección y procesamiento de recursos locales. Otras incluyeron acondicionar el espacio, manejar sustancias colorantes y ejecutar una gran cantidad de motivos sobre una variedad de soportes, tanto mobiliares como fijos en el caso de las paredes y techo de la cueva. Esta forma particular de usar el sitio y de producir arte rupestre, ocurre en el marco más amplio de cambios notables en el registro arqueológico macrorregional vinculados con el uso de nuevas tecnologías, como la cerámica y el arco y la flecha (Hajduk et al. 2011; Gordón et al. 2017), sumado a la marcación sistemática mediante arte rupestre del paisaje del noroeste de Patagonia, incluidos los espacios estacionales de altura de los Andes (Romero Villanueva et al. 2020). Estos cambios suceden en sintonía con aumentos poblacionales inferidos para los últimos 3.000 años a partir de evidencias arqueológicas, radiocarbónicas y de ADN mitocondrial disponibles a escala suprarregional (Barberena et al. 2015b; Perez et al. 2016; Gordón et al. 2019; Timpson et al. 2021; entre otros). Se considera plausible que este nuevo contexto sociodemográfico macrorregional haya activado la circulación de nuevos y variados tipos de información cuyos correlatos materiales pueden identificarse en escalas demográficas y/o espaciales diversas (macrorregión, región, sitio).

De esta manera, a pesar de las discontinuidades y baja intensidad con la cual fue ocupado $\mathrm{CH} 1$, su arte rupestre resulta un insumo clave para complejizar la historia de uso humano del sitio y la región a través del tiempo. En particular, permitió argumentar que esta evidencia desempeñó un rol clave -aunque versátil-en la construcción de CH1 como lugar persistente (sensu Schlanger 1992) dentro de la geografía social de los grupos móviles que ocuparon la LBB durante el Holoceno (Romero Villanueva 2021). A su vez, también ofrece información relevante que sugiere que las redes de movilidad e informacionales en escala macrorregional, presentan características diferenciales a lo largo del Holoceno. No obstante, se entiende que ningún espacio discreto dentro de un sistema humano móvil, es representativo por sí solo de las esferas de acción humana en escalas más amplias. Por ello, la información a escala de sitio (CH1) y región (LBB) es integrada y, posteriormente, comparada en relación con lo observado por otros investigadores en regiones cercanas del noroeste de Patagonia. 
Escala macrorregional: redes de información e interacción social intergrupal en el noroeste de Patagonia durante el Holoceno tardio

La producción rupestre en el sitio $\mathrm{CH} 1$, y en la región LBB en general, se intensifica y diversifica en el Holoceno tardío (últimos 3.000 años) (Romero Villanueva 2019a, 2021). A partir de este momento, también se verifica una marcación sistemática mediante arte rupestre en diversas regiones cercanas ubicadas en ambas vertientes de los Andes, incluidos los espacios estacionales de altura del noroeste de Patagonia (ver detalles en Romero Villanueva et al. 2020). Las zonas con arte rupestre referidas incluyen diversas regiones del actual territorio argentino, tales como el norte de la provincia del Neuquén (LBB, cuenca superior-media del río Neuquén y cuenca del río Curi Leuvú) y el sur de la provincia de Mendoza, así como otras ubicadas en el actual territorio chileno (región cordillerana del Maule) (figura 2). Por cuestiones de espacio, se remite al lector a publicaciones recientes fácilmente accesibles, donde se analiza y sistematiza la información rupestre para estas zonas y se referencian las citas correspondientes (Barberena et al. 2017:tabla 2 y figura 4; Romero Villanueva et al. 2020:tablas 2 y 3 y figuras 5, 6, y 7). Estos análisis permitieron identificar tanto semejanzas como diferencias entre los conjuntos de arte rupestre de las áreas comparadas, al tiempo que se evaluó el grado de conectividad entre las tierras altas y bajas andinas mediante análisis SIG de modelado de la estacionalidad y caminos de menor costo (Barberena et al. 2017; Romero Villanueva et al. 2020).

Entre las similitudes observadas en el arte rupestre del noroeste de Patagonia resaltan el predominio de los motivos grabados, los motivos no figurativos por sobre los figurativos -si bien en proporciones variables-, y la presencia de un amplio rango de tipos de motivos compartidos, entre los que se destacan distintas líneas paralelas, figuras de simetría axial, figuras adosadas (triángulos, rombos) y cruciformes (Barberena et al. 2017:tabla 2 y figura 4; Romero Villanueva et al. 2020:tablas 2 y 3 y figuras 5, 6, y 7). Se entiende que estas semejanzas dan cuenta del uso de un código visual compartido a escala macrorregional durante el Holoceno tardío en el noroeste de Patagonia que sustentó lazos de comunicación e interacción social entre grupos humanos que ocuparon espacios geográfica y ecológicamente contrastantes, sujetos a condiciones variadas para el uso humano (por ej. anuales vs. estacionales, nodales vs. internodales) (Barberena et al. 2017:tabla 2 y figura 4; Romero Villanueva et al. 2020a:tablas 2 y 3 y figuras 5, 6, y 7). Estos vínculos habrían sentado las bases para el establecimiento de redes de seguridad (sensu Whallon 2006), de gran valor adaptativo en ambientes como el del noroeste de Patagonia, dada su baja conectividad geográfica (sensu Fitzhugh et al. 2011) durante una gran parte del año.

No obstante, también se observaron diferencias entre regiones en relación con la densidad de motivos, los porcentajes variables de las categorías representadas y la presencia-ausencia de determinadas categorías y tipos de motivos (Barberena et al. 2017:tabla 2 y figura 4; Romero Villanueva et al. 2020:tablas 2 y 3 y figuras 5, 6, y 7). En particular, las áreas ubicadas a mayor altitud, cuyo uso es estacional, resaltan por presentar las mayores cantidades de motivos. En una de ellas -región cordillerana del Maule, en Chile-, Niemeyer y Weisner (1972-73) definieron tempranamente el estilo Guaiquivilo que, según desarrollos posteriores de otros autores, se caracterizaría por combinar morfologías presentes en los estilos de Pisadas, Paralelas y Grecas del arte rupestre de la Patagonia argentina (sensu Menghin 1957). Sobre la base de estas observaciones, preliminarmente se sugirió que esta zona concentraría la mayor diversidad de tipos de motivos documentados, incluyendo algunos que son característicos de otras regiones de Patagonia, pero se encontrarían ausentes (o en muy baja frecuencia) en las demás áreas de la macrorregión considerada (Belardi et al. 2016; Barberena et al. 2017; Romero Villanueva 2019a; Romero Villanueva et al. 2020).

En forma inicial, estas divergencias se consideraron indicativas de una circulación diferencial de información entre regiones, en función de su distinta jerarquía para el uso humano (Romero 
Villanueva 2019a; Romero Villanueva et al. 2020). Sin embargo, aún resta evaluar en profundidad qué tipo(s) de información transmitida en el marco de qué rol(es) desempeñados por el arte rupestre. En relación con ello, es probable que los espacios estacionales de altura del noroeste de Patagonia -sectores $>2.000$ m s.n.m. de la región cordillerana del Maule y de las cordilleras de los Andes y del Viento-, dada su alta productividad estival, hayan sido ocupados durante esa estación por grupos humanos provenientes de diferentes áreas de menor altitud emplazadas en los actuales territorios de Chile (tierras bajas de la región del Maule) y de Argentina (cuenca del río Neuquén y espacios al este de la cordillera del Viento y del Campo Volcánico Tromen), que representarían nodos demográficos diferentes pero articulados entre sí, sujetos a un uso humano comparativamente más prolongado, recurrente y/o intenso (Barberena et al. 2017; Romero Villanueva et al. 2020).

Por lo tanto, a futuro se buscará explorar en forma sistemática si las diferencias interregionales observadas en el arte rupestre del noroeste de Patagonia durante el Holoceno tardío pueden resultar informativas sobre la marcación en el paisaje de niveles variables de heterogeneidad social. Se considera plausible que, en el marco de códigos visuales macrorregionales compartidos, orientados a fomentar la circulación de información y el establecimiento y mantenimiento de redes de cohesión en escala social amplia, ciertos motivos o conjuntos de motivos, pudieron desempeñar un rol emblémico (sensu Wiessner 1983) en una escala socioespacial y demográfica menor para canalizar la marcación de diferentes identidades grupales (cfr. Bernardini 2005). Numerosos casos arqueológicos y etnográficos sugieren que la representación de estilos que expresan la identidad grupal puede resultar un mecanismo social apropiado para facilitar y regular interacciones en entornos socialmente complejos (por ej. competencia intergrupal, cooperación o control impuesto en relación con la consecución de metas comunes) donde las redes sociales se hallan más desarrolladas y se discuten límites sociales (Wobst 1977; Wiessner 1983; Hartley 1992; David y Lourandos 1998; McDonald y Veth 2006; entre otros). Este podría ser el caso de los espacios estacionales de altura del noroeste de Patagonia, al menos durante el Holoceno tardío, potencialmente sujetos a un uso de tipo comunal (sensu Eerkens 1999) dadas sus características biogeográficas (Barberena et al. 2017). Así, el uso compartido de estos espacios y sus recursos pudo involucrar la interacción entre entidades con diferencias etnolingüísticas o de otro tipo, que se puedan ver reflejadas en la conformación de reservorios de información con diversos grados de diferenciación (David y Lourandos 1998; Carden 2008; McDonald y Veth 2006, 2013; McDonald 2017; Troncoso et al. 2016; entre otros).

Por el momento, lo que estos resultados y la evidencia rupestre en particular indican con certeza es que los espacios estacionales de altura del noroeste de Patagonia tuvieron una gran jerarquía en las redes macrorregionales de comunicación visual y circulación de información, al tiempo que desempeñaron roles variables durante el Holoceno tardío (Barberena et al. 2017; Romero Villanueva 2019a; Romero Villanueva et al. 2020). Por un lado, constituyeron barreras biogeográficas durante gran parte del ciclo anual. Por el otro, en época estival, actuaron como zonas de convergencia poblacional (sensu Belardi y Goñi 2006; Re 2010) sujetas a un potencial uso comunal (Barberena et al. 2017; Romero Villanueva 2019a; Romero Villanueva et al. 2020). En suma, este análisis permite conceptualizar a este sector de los Andes como un espacio versátil en términos ecológicos, demográficos y sociales, que desempeñó roles variados en la historia poblacional del noroeste de Patagonia.

\section{REFLEXIONES FINALES}

En este trabajo se explicitaron los lineamientos conceptuales de una perspectiva biogeográfica para estudiar procesos de comunicación visual, circulación de información e interacción social 
mediante el análisis multiescalar y multidimensional del arte rupestre. Se entiende que esta práctica de publicar la agenda de una investigación, no solo contribuye a la sistematización de los datos rupestres propios, sino que resulta útil para los colegas interesados en ellos. Asimismo, dado que la propuesta puede ser replicada en otros contextos temporales y espaciales, no necesariamente restringidos a sociedades móviles y/o cazadoras-recolectoras de la región patagónica, existe un amplio potencial para el desarrollo de una arqueología comparativa con una base biogeográfica tanto a nivel regional, como nacional e internacional. Además, estos lineamientos pueden ser aplicados desde las primeras instancias de la investigación, ya que facilitan la identificación de patrones y situaciones excepcionales, así como de semejanzas y diferencias, que pueden resultar de utilidad para orientar los pasos posteriores e interpretar las tendencias observadas. Desde luego, dado que algunos de ellos son específicos al caso referido como ejemplo de aplicación, deberán ser ajustados en función de las particularidades de cada caso.

El aspecto clave del presente enfoque radica en asumir y afrontar, en forma sistemática y teórica y metodológicamente informada, la potencial versatilidad de los roles desempeñados y tipos de información transmitidos por el arte rupestre en el pasado. El camino elegido para ello implica el abordaje holístico de sus múltiples dimensiones, escalas de expresión y relaciones contextuales. Si bien cada una de estas vías de entrada analítica son informativas por sí mismas, el potencial heurístico de cada una se ve amplificado al integrarlas en forma comparativa. Así, los análisis contextuales detallados y el cambio estratégico de escalas, sumado a la consideración de las dimensiones formales, contextuales y arqueométricas del arte rupestre, contribuye a refinar las interpretaciones sobre esta evidencia en escala arqueológica. En gran medida, esto se debe a que las distintas relaciones, segmentaciones y dimensiones identificadas y analizadas separadamente son recortes analíticos (necesarios, pero artificiales) de vínculos y procesos pluridimensionales y continuos. Ante esta complejidad, el empleo de criterios claros definidos en forma explícita, también contribuye a generar datos rupestres sistemáticos con mayor potencial argumentativo, que estén a la altura de la retroalimentación analítica propuesta.

En particular, en el caso de aplicación utilizado aquí como ejemplo, el abordaje en simultáneo de diferentes dimensiones del arte rupestre -analizado en sus contextos de ejecución y uso particulares, en diferentes escalas jerárquicas e inclusivas- demostró el potencial de elegir la opción compleja, multidimensional y multiescalar como vía de entrada para discutir problemáticas arqueológicas que también se caracterizan por ello. Así, en el caso de esta propuesta, el problema se concibió como parte de la solución.

Las tareas a futuro son múltiples y variadas. Por un lado, se continuará publicando en detalle diversos aspectos de esta propuesta, sistematizada en la tesis doctoral inédita de la autora (Romero Villanueva 2019a), a fin de compartir las ideas allí vertidas con el conjunto de la comunidad académica. Se encuentran en redacción y evaluación artículos donde se detalla en forma exhaustiva los lineamientos metodológicos generales de la propuesta y, en particular, aquellos diseñados e implementados para contextualizar temporalmente el arte rupestre (Romero Villanueva 2019b; Romero Villanueva et al. 2021 b y c). Por otro lado, se profundizará en las distintas discusiones ya iniciadas en múltiples escalas espaciales. A nivel local, se profundizará en el análisis de las características del arte rupestre de sitios como CH1 y CY para identificar cambios y continuidades en su producción rupestre a lo largo del tiempo y, en particular, durante momentos tardíos. A nivel regional, se evaluarán las similitudes y diferencias registradas en los motivos rupestres de la LBB en relación con la conectividad observada entre los sitios mediante diversos análisis SIG. Estos resultados, en conjunto con nuevos elementos conceptuales, ofrecerán información relevante para ahondar en la jerarquización visual diferencial observada en rangos de acción emplazados en espacios andino-patagónicos. Asimismo, a escala macrorregional, se implementarán diversos análisis (por ej. formales, espaciales mediante SIG, de redes sociales) que ofrecerán medidas cuali-cuantitativas sistemáticas sobre el grado de conectividad existente entre motivos, sitios y 
espacios andinos cordilleranos y pericordilleranos emplazados entre los $36^{\circ}$ a $37^{\circ}$ de latitud sur (región del Maule, en Chile, y norte del Neuquén, Argentina). A su vez, la discusión de hipótesis de base etnográfica, etnohistórica y arqueológica permitirá ahondar sobre diversos aspectos vinculados con el acceso y el uso de estos espacios (por ej. vectores geográficos dominantes, mecanismos sociales regulares del acceso a espacios de uso comunal) (Romero Villanueva et al. 2021d; Romero Villanueva y Barberena 2021). Así, el estudio multiescalar de procesos de comunicación visual, circulación de información e interacción social mediante arte rupestre, desde el enfoque aquí propuesto, se presenta como una vía analítica prometedora para abordar a futuro la compleja articulación entre imágenes rupestres, identidades sociales y lugares socialmente significativos en una escala arqueológica.

\section{AGRADECIMIENTOS}

Este artículo resume información desarrollada durante mi doctorado. Por lo tanto, agradezco a mis directores -Anahí Re y Ramiro Barberena- y consejeros de estudios -Rafael Goñi y Mercedes Podestá- por haberme guiado en ese proceso. También estoy agradecida y honrada de que Natalia Carden, Dánae Fiore y Luciano Prates hayan sido jurados de mi tesis. Oportunamente, todos efectuaron comentarios relevantes sobre las ideas allí vertidas que contribuyen a mejorar las comunicadas aquí y, a futuro, para un público más amplio. En este trabajo en particular, también resultaron una gran contribución las sugerencias efectuadas por dos evaluares/as anónimos/as a quienes les agradezco el tiempo y la dedicación. No obstante, todo lo reproducido en este texto es de mi exclusiva responsabilidad. Numerosos colegas-amigos colaboraron en las tareas de campo y laboratorio cuyos resultados son presentados y discutidos aquí. A todos ellos, muchas gracias por sus aportes, el tiempo compartido y los recuerdos. Los trabajos referidos fueron financiados por una Beca Doctoral del CONICET y diversos proyectos (PICT 2010-1856, 2014-0940, 20160062, PIP 301). Estas tareas siempre contaron con el valioso apoyo de autoridades provinciales (Carlos Cides, Claudia Della Negra), municipales (Juvenal Urrutia, Paulina Valenzuela) y de los pobladores de Barrancas y Buta Ranquil a quienes agradezco por su constante acompañamiento. Por último, pero no menos importante, agradezco de corazón a mis personas favoritas, que compartieron y comparten conmigo el detrás de escena de tantos viajes de campo, horas de análisis y párrafos redactados.

\section{NOTAS}

1 El uso del concepto arte siempre requiere precisiones dadas las posturas encontradas respecto de su aplicación. Debido a múltiples razones ya explicitadas (Romero Villanueva 2016, 2019a), se opta por utilizarlo, sin por ello asumir que su producción/uso se haya limitado a consideraciones de tipo estético ni que su estudio se deba abordar solamente desde ese punto de vista, ya que los roles desempeñados pudieron ser múltiples y simultáneos (incluido el estético) por lo que deben ser investigados caso a caso de manera contextual.

2 El uso del concepto paisaje siempre requiere precisiones dadas las distintas definiciones existentes respecto de su aplicación, en particular en relación con el estudio del arte rupestre. Aunque esta tarea excede los objetivos del presente trabajo, se señala, brevemente, que se adopta una definición relacional que refiere a la red de lugares y los caminos que los unen, a partir de la cual los grupos humanos experimentan, significan, organizan y viven su vida. Este entramado, históricamente situado, se co-constituye a partir de relaciones no-lineales entre aspectos humanos y no humanos (Dincauze 2000; David y Thomas 2008; Walker 2012; entre otros).

3 En parte, esto se debería al costo/beneficio asociado a determinadas decisiones como la inversión laboral necesaria para la ejecución de las imágenes, la durabilidad potencial de los materiales que les hacen de 
soporte, así como el alcance espacial y social de circulación de la información transmitida, entre otros factores que pueden ser evaluados a partir de múltiples variables (Fiore 2006, 2009; Troncoso 2006; Carden 2008; Re 2010; Romero Villanueva 2019a; entre otros).

4 Para una correcta integración de la información generada fue necesario explicitar exhaustivamente las diversas unidades y variables de análisis consideradas (para el nivel de las imágenes, los soportes y los sitios) que no son mencionadas aquí por cuestiones de espacio (ver detalles en Romero Villanueva 2019a). Del mismo modo, también se han explicitado los indicadores (relativos y absolutos) y métodos utilizados para establecer tendencias temporales para el arte rupestre, así como las técnicas y los protocolos implementados en el trabajo de campo y en el análisis en laboratorio, incluyendo los análisis arqueométricos.

5 CH1 fue originalmente excavado por Fernández y equipo en los años setenta. Los resultados de estos trabajos no fueron publicados, a excepción de un fechado radiocarbónico sobre materia orgánica de procedencia estratigráfica desconocida, que arrojó una edad de ca. 11000 años AP (Cordero et al. 2002).

6 A nivel funcional, la baja tasa de descarte artefactual en $\mathrm{CH} 1$ es significativa ya que es el sitio muestreado en forma más intensa en la LBB, tanto a nivel de superficie como estratigrafía. Esto podría vincularse a la presencia local de la fuente de obsidiana Cerro Huenul, con lo cual hay actividades de cantera taller en contextos por fuera del reparo (Rughini et al. 2020).

7 Sobre estos principios de los procesos de comunicación se asienta la noción de estilo como estrategia social sensu Wobst (1977) cuya función principal permite vincular miembros de una comunidad que no están en contacto verbal constante, haciendo que las interacciones sean más predecibles y menos estresantes.

\section{REFERENCIAS BIBLIOGRÁFICAS}

Acevedo, A. y D. F. Fiore (2020). Imágenes, códigos y comunicación: un análisis del arte rupestre en el Extremo Sur del Macizo del Deseado (Patagonia, Argentina). Arqueología 26(2): 127-155. DOI: 10.34096/ arqueologia.t26.n2.5835

Aschero, C. (1988). Pinturas rupestres, actividades y recursos naturales: un encuadre arqueológico. En H. Yacobaccio (ed.), Arqueología Contemporánea Argentina. Actualidad y Perspectivas: 109-145. Buenos Aires, Ediciones Búsqueda.

Aschero, C. (1997). De cómo interactúan emplazamientos, conjuntos y temas. Revista del Museo de Historia Natural de San Rafael 16(1-4): 17-28.

Aschero, C. (2000). El poblamiento del territorio. En M. Tarragó y J. E. Burucúa (eds.), Nueva Historia Argentina. Los pueblos originarios y la conquista, Volumen 1: 16-59. Buenos Aires, Sudamericana.

Bailey, G. (1983). Concepts of time in Quaternary prehistory. Annual Review of Anthropology 12: 165-192. DOI: 10.1146/annurev.an.12.100183.001121

Barberena, R. (2008). Arqueología y biogeografía humana en Patagonia meridional. Buenos Aires, Sociedad Argentina de Antropología.

Barberena, R. (2013). Biogeografía, competencia y demarcación simbólica del espacio: modelo arqueológico para el norte de Neuquén. Intersecciones en Antropología 14: 367-381.

Barberena, R., K. Borrazzo, A. A. Rughini, G. Romero, M. P. Pompei, C. Llano, M. E. de Porras, V. Durán, Ch. R. Stern, A. Re, D. Estrella, A. Forasiepi, F. J. Fernández, M. Chidiak, L. Acuña, A. Gasco y M. N. Quiroga (2015a). Perspectivas arqueológicas para Patagonia septentrional: sitio Cueva Huenul 1 (provincia del Neuquén, Argentina). Magallania 43 (1): 1-27. DOI: 10.4067/S0718-22442015000100009

Barberena, R., L. Prates y M. E. de Porras (2015b). The human occupation of northwestern Patagonia (Argentina): Paleoecological and chronological trends. Quaternary International 356: 111-126. DOI: 10.1016/j.quaint.2014.09.055 
Relaciones de la Sociedad Argentina de Antropología 46 (2), julio-diciembre 2021: 595-628

Barberena, R., G. RomeroVillanueva, G. Lucero, M.V.Fernández y M. N. Quiroga (2017). Espacios internodales en Patagonia septentrional: biogeografía, información y mecanismos sociales de interacción. Estudios Atacameños. Arqueología y Antropología Surandina 56: 57-75. DOI: 10.4067/S0718-10432017005000006.

Barton, C. M., G. A. Clark y A. E. Cohen (1994). Art as information: explaining Upper Paleolithic art in Western Europe. World Archaeology 26(2): 185-207. DOI: 10.1080/00438243.1994.9980272

Berón, M. A., A. Di Biase, M. G. Musaubach y F. Páez (2017). Enclaves y espacios internodales en la dinámica de poblaciones en el Wall-Mapu. Aportes desde la arqueología pampeana. Estudios Atacameños. Arqueología y Antropología Surandina 56: 253-272. DOI: 10.4067/S0718-10432017005000008

Binford, L. R. (1982). The Archaeology of Place. Journal of Anthropological Archaeology 1: 5-31. DOI: 10.1016/0278-4165(82)90006-X

Binford, L. R. (2001). Constructing frames of reference. An analytical method for archaeological theory building using ethnographic and environmental data sets. Los Ángeles, University of California Press.

Bird, D. W. y J. F. O'Connell (2006). Behavioral ecology and archaeology. Journal of Archaeological Research 14: 143-188. DOI: 10.1007/s10814-006-9003-6

Belardi, J. B. (2020). Las condiciones bajo las cuales y la limitación saludable: puertas al conocimiento arqueológico. Comechingonia. Revista de Arqueología 24(1): 111-120. DOI: 10.37603/2250.7728.v24. $\mathrm{n} 1.28243$

Belardi, J. B., R. Barberena, R. Goñi y A. Re (2016). The Development of a Legacy: Evolution, Biogeography and Archaeological Landscapes. En M. Cardillo y H. Muscio (eds.), Darwin's Legacy: The Status of Evolutionary Archaeology in Argentina: 89-98. Oxford, Archaeopress.

Belardi, J. B. y R. A. Goñi (2006). Representaciones rupestres y convergencia poblacional durante momentos tardíos en Santa Cruz (Patagonia argentina). El caso de la meseta del Strobel. En D. Fiore y M. M. Podestá (eds.), Tramas en la piedra. Producción y usos del arte rupestre: 13-27. Buenos Aires, WAC, SAA y AINA.

Bernardini, W. (2005). Reconsidering Spatial and Temporal Aspects of Prehistoric Cultural Identity: A Case Study from the American Southwest. American Antiquity 70(1): 31-54. DOI: 10.2307/40035267

Borrero, L. A. (1989-90). Evolución cultural divergente en la Patagonia austral. Anales del Instituto de la Patagonia (Serie Ciencias Sociales) 19: 133-139.

Borrero, L. A. (1994-95). Arqueología de la Patagonia. Palimpsesto. Revista de Arqueología 4: 9-56.

Borrero, L. A. (2011). La arqueología de cazadores-recolectores: ambiente y conocimiento. CazadoresRecolectores del Cono Sur 4: 43-58.

Borrero, L. A. (2013). Paisajes desconocidos, geografía cultural y tafonomía total. Anuario de Arqueología, Rosario 5: 17-30.

Borrero, L. A. (2020). Los 'modelos de situaciones excepcionales' y el estudio de las sociedades de cazadores y recolectores. Comechingonia. Revista de Arqueología 7: 107-127. DOI: 10.37603/2250.7728.v24.n1.28242

Carden, N. (2008). Imágenes a través del tiempo. Arte rupestre y construcción social del paisaje en la Meseta Central de Santa Cruz. Buenos Aires, Sociedad Argentina de Antropología.

Carden, N., F. Borella y M. Cardillo (2020). Rock art relatedness and circulation paths in Northeast Patagonia, Argentina. Rock Art Research 37 (2): 184-203. 
Carden, N. y L. Miotti (2020). Unraveling rock art palimpsests through superimpositions: The definition of painting episodes in Los Toldos (southern Patagonia) as a baseline for chronology. Journal of Archaeological Science: Reports 30: 102265. DOI: 10.1016/j.jasrep.2020.102265

Charlin, J. y L. A. Borrero (2012). Rock art, inherited landscapes, and human populations in Southern Patagonia. En J. McDonald y P. Veth (eds.), A Companion to Rock Art: 381-397. Blackwell Publishing Ltd.

Conkey, M. (1978). Style and information in cultural evolution: toward a predictive model for the Paleolithic. En C. Redman (ed.), Social Archeology: Beyond Subsistence and Dating: 61-85. New York, Academic Press.

Conkey, M. (1984). To Find Ourselves: Art and Social Geography of Prehistoric Hunter-Gatherers. En C. Schrire (ed), Past and Present in Hunter-Gatherer Studies: 253-276. New York, Academic Press.

Conkey, M. (1997). Mobilizing Ideologies: Paleolithic “Art”, GenderTrouble, and Thinking about Alternatives. En L. Hager (ed.), Women in Human Evolution: 172-207. London, Routledge.

Cordero, R., S. Lanzelotti y H. Panarello (2002). INGEIS Radiocarbon Laboratory Dates IV. Radiocarbon 44(1): 181-193. DOI: $10.1017 /$ S003382220006478X

David, B. y H. Lourandos (1998). Rock art and socio-demography in northeastern Australian prehistory. World Archaeology 30(2): 193-219. DOI: 10.1080/00438243.1998.9980407

David, B. y J. Thomas (eds.) (2008). Handbook of Landscape Archaeology. Walnut Creek, Left Coast Press.

Delcourt, H. R. y P. A. Delcourt (1988). Quaternary landscape ecology: relevant scales in space and time. Landscape Ecology 2(1): 23-44. DOI: 10.1007/BF00138906

Dincauze, D. F. (2000). Environmental Archaeology: Principles and Practice. Cambridge, Cambridge University Press.

Domingo Sánz, I., D. Fiore y S. K. May (eds.) (2008). Archaeologies of Art: Time, Place, and Identity in Rock Art, Portable Art, and Body Art. Left Coast Press.

Eerkens, J. W. (1999). Common Pool Resources, Buffer Zones, and Jointly Owned Territories: HunterGatherer Land and Resource Tenure in Fort Irwin, Southeastern California. Human Ecology 27(2): 297-318. DOI: $10.1023 / \mathrm{A}: 1018777311943$

Fernández, J. (1974-76). Estudios sobre el arte rupestre de la provincia del Neuquén. Anales de Arqueología y Etnología 29-31: 5-36.

Fernández, J. (1978). Corpus de arte rupestre neuquino. $1^{\circ}$ parte. Revista del Museo Provincial 1: 17-93.

Fernández, M. V., R. Barberena, M. Giesso, A. A. Rughini, V. Cortegoso, M. D. Glascock, V. Durán, G. Romero Villanueva, K. Borrazzo, G. Lucero, R. Garvey y B. L. MacDonald (2017). Obsidian geochemistry, geoarchaeology, and lithic technology in northwestern Patagonia (Argentina). Journal of Archaeological Science: Reports 13: 372-381. DOI: 10.1016/j.jasrep.2017.04.009

Fiore, D. (2006). Poblamiento de imágenes: arte rupestre y colonización de la Patagonia. Variabilidad y ritmos de cambio en tiempo y espacio. En D. Fiore y M. M. Podestá, Tramas en la Piedra. Producción y usos del arte rupestre: 43-61. Buenos Aires, WAC, SAA y AINA.

Fiore, D. (2009). La materialidad del arte. Modelos económicos, tecnológicos y cognitivos visuales. En R. Barberena, K. Borrazzo y L. A. Borrero (eds.), Perspectivas actuales en Arqueología Argentina: 123-154. Buenos Aires, CONICET-IMHICIHU. 
Fiore, D. y A. Acevedo (2018). Paisajes rupestres. La identificación de patrones de producción y distribución de arte parietal en escalas espaciales amplias (Cañadón Yaten Guajen, Santa Cruz, Patagonia argentina). Arqueología 24(2): 177-207. DOI: 10.34096/arqueologia.t24.n2.5006

Fiore, D. y M. M. Podestá (2006). Introducción. Las tramas conceptuales del arte rupestre. En D. Fiore y M. M. Podestá (eds.), Tramas en la piedra. Producción y usos del arte rupestre: 13-27. Buenos Aires, WAC, SAA y AINA.

Fitzhugh, B., S. C. Phillips y E. Gjesfjeld (2011). Modeling hunter-gatherer information networks: An archaeological case study from the Kuril Islands. En R. Whallon, W. A. Lovis y R. Hitchcock (eds.), Information and its Role in Hunter-Gatherer Bands: 85-115. Los Ángeles, UCLA Cotsen Institute of Archaeology Press.

Foley, R. (1981). A Model of Regional Archaeological Structure. Proceedings of the Prehistoric Society 47: 1-17. DOI: 10.1017/S0079497X00008823

Gamble, C. (1982). Interaction and Alliance in Paleolithic society. Man 17: 92-107. DOI: 10.2307/2802103

Gamble, C. (1990). El Poblamiento Paleolítico de Europa. Madrid, Editorial Crítica.

Gamble, C. (1993). Timewalkers. The Prehistory of Global Colonization. Cambridge, Harvard University Press.

Gjesfjeld, E., M. A. Etnier, K. Takase, W. A. Brown y B. Fitzhugh (2020). Biogeography and adaptation in the Kuril Islands, Northeast Asia. World Archaeology 51(3): 429-453. DOI: 10.1080/00438243.2019.1715248

Goñi, R. (2010). Cambio climático y poblamiento humano durante el Holoceno tardío en Patagonia meridional. Una perspectiva arqueológica. Tesis Doctoral inédita, Facultad de Filosofía y Letras, Universidad de Buenos Aires.

Gordón, F., R. Barberena y V. Bernal (eds.) (2017). El poblamiento humano del norte del Neuquén: Estado actual del conocimiento y perspectivas. Ciudad Autónoma de Buenos Aires, Aspha.

Gordón, F., M. Beguelin, P. Novellino y F. Archuby (2019). Inferencias paleodemográficas en el noroeste de Patagonia a partir del sitio Aquihuecó, provincia del Neuquén, Argentina. Chungara 51: 363-380. DOI: 10.4067/S0717-73562019005001302

Grasset, S., A. Nuevo-Delaunay, J. Álvarez, A. Maldonado y C. Méndez (2021). New Chronostratigraphic Records of the Early-to-Middle Holocene in the North-Central Region of Chile Indicate Andean Foothills Housed Hunter-Gatherers during Pulses of Extreme Aridity. The Holocene 31(4): 1-15. DOI: $10.1177 / 09596836211011653$

Haas, R. y S. L. Kuhn (2019). Forager Mobility in Constructed Environments. Current Anthropology 60(4): 499-535. DOI: $10.1086 / 704710$

Hajduk, A., A. M. Albornoz y M. J. Lezcano (2011). Espacio, cultura y tiempo: el corredor bioceánico desde la perspectiva arqueológica. En P. Navarro Floria y W. Delrio (comps.), Cultura y espacio. AraucaníaNorpatagonia: 262-292. Bariloche, Universidad Nacional de Río Negro.

Halstead, P. y J. O'Shea (1989). Introduction: cultural responses to risk and uncertainty. En P. Halstead y J. O’Shea (eds.), Bad Year Economics: 1-7. Cambridge, Cambridge University Press.

Harcourt, A. (2012). Human biogeography. Berkeley, University of California Press.

Harman, J. (2008). Using Decorrelation Stretch to Enhance Rock Art Images. Disponible en: https://www. dstretch.com 


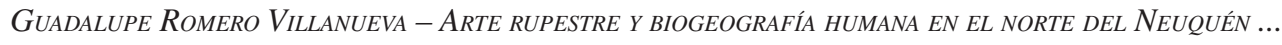

Hartley R. J. (1992). Rock art on the Northern Colorado Plateau: variability in content and context. Aldershot, Avebury.

Holdaway, S. J. y L. A. Wandsnider (2006). Temporal Scales and Archaeological Landscapes from the Eastern Desert of Australia and Intermontane North America. En G. Lock y B. Molyneaux (eds.), Confronting scales in Archaeology: 183-202. Kluwer, New York.

Jochim, M. A. (1981). Strategies for Survival, Cultural Behavior in an Ecological Context. London, Academic Press.

Jochim, M. A. (1983). Paleolithic cave art in ecological perspective. En G. Bailey (ed.), Hunter-gatherer economy in prehistory: 212-219. Cambridge, Cambridge University Press.

Kelly, R. L. (1995). The Foraging Spectrum. Diversity in Hunter-Gatherer Lifeways. Washington, Smithsonian Institution Press.

Kelly, R. L. (2013). The Lifeways of Hunter-Gatherers: The Foraging Spectrum. Cambridge, Cambridge University Press.

Lahr, M. M. y R. Foley (1998). Towards a Theory of Modern Human Origins: Geography, Demography, and Diversity in Recent Human Evolution. Yearbook of Physical Anthropology 41: 137-176. DOI: 10.1002/ (sici)1096-8644(1998)107:27+<137::aid-ajpa6>3.0.co;2-q

Langley, M. C. (2013). Storied landscapes makes us (Modern) Human: Landscape socialization in the Palaeolithic and consequences for the archaeological record. Journal of Anthropological Archaeology 32(4): 614-629. DOI: 10.1016/j.jaa.2013.10.001

Layton, R. (1991). The Anthropology of Art. $2^{\text {nd }}$ edition. Cambridge, Cambridge University Press.

Layton, R. (1992). Australian Rock Art. A New Synthesis. Cambridge, Cambridge University Press.

Llano, C. (2015). On optimal use of a patchy environment: Archaeobotany in the Argentinean Andes (Argentina). Journal of Archaeological Science 54: 182-192. DOI: 10.1016/j.jas.2014.12.002

Llano, C., M. E. de Porras, R. Barberena, A. Timpson, M. O. Beltrame y E. J. Marsh (2020). Human resilience to Holocene climate changes inferred from rodent middens in drylands of northwestern Patagonia (Argentina). Palaeogeography, Palaeoclimatology, Palaeoecology, 109894. DOI: 10.1016/j.palaeo.2020.109894

Lomolino, M. V., B. R. Riddle y J. H. Brown (2010). Biogeography. Fourth Edition. Massachusetts, Sinauer Associates Inc. Sunderland.

Loubser, J. (2013). A Holistic and Comparative Approach to Rock Art. Time and Mind: The Journal of Archaeology, Consciousness and Culture 6 (1): 29-36. DOI: 10.2752/175169713X13500468476448

MacDonald, B. L., J. C. Chatters, E. G. Reinhardt, F. Devos, S. Meacham, D. Rissolo, B. Rock, C. Le Maillot, D. Stalla, M. D. Marino, E. Lo y P. L. Erreguerena (2020). Paleoindian ochre mines in the submerged caves of the Yucatán Peninsula, Quintana Roo, Mexico. Science Advances 6(27): p.eaba1219. DOI: 0.1126/sciadv. aba1219

MacDonald, B. L., D. Stalla, X. He, F. Rahemtulla, D. Emerson, P. A. Dube, M. R. Maschmann, C. E. Klesner y T. A. White (2019). Hunter-Gatherers harvested and heated microbial biogenic iron oxides to produce rock art pigment. Scientific Reports 9: 17070. DOI: 10.1038/s41598-019-53564-w

Martel,A., S. Rodríguez Curletto y E. Del Bel (2012).Arte Rupestre y Espacios de Memoria: las representaciones 
Relaciones de la Sociedad Argentina de Antropología 46 (2), julio-diciembre 2021: 595-628

del sitio Confluencia (Antofagasta de la Sierra, Catamarca, Argentina). Revista Chilena de Antropología 25(1): 121-162. DOI: 10.5354/0719-1472.2012.20290

Martínez G. (ed.) (2017). Arqueología de cazadores-recolectores del curso inferior del Río Colorado (Provincia de Buenos Aires, Argentina). Aportes al conocimiento de las ocupaciones humanas Pampeano-Patagónicas. Olavarría, INCUAPA-CONICET y UNICEN.

McDonald, J. (2008). Dreamtime superhighway: an analysis of Sydney Basin rock art and prehistoric information exchange. Perth, ANU Press.

McDonald, J. (2017). Discontinuities in Australian arid zone rock art: graphic indicators for changing social complexity across space and through time. Journal of Anthropological Archaeology 46: 53-67. DOI: 10.1016/j.jaa.2016.08.005

McDonald, J. y P. Veth (2006). Rock art and social identity: a comparison of graphic systems operating in arid and fertile environments in the Holocene. En I. Lilley (ed.), Archaeology of Oceania: Australia and the Pacific Islands: 96-115. Oxford, Blackwell.

McDonald, J. y P. Veth (2011). Information exchange among Hunter-Gatherers of the western desert of Australia. En R. Whallon, W. A. Lovis y R. Hitchcock (eds.), Information and its Role in Hunter-Gatherer Bands: 221-233. Los Ángeles, UCLA Cotsen Institute of Archaeology Press.

McDonald, J. y P. Veth (eds.) (2012). A Companion to Rock Art. Blackwell Publishing Ltd.

McDonald, J. y P. Veth (2013). The Archaeology of Memory: The Recursive Relationship of Martu Rock Art and Place. Anthropological Forum: A Journal of Social Anthropology and Comparative Sociology 23(4): 367-386. DOI: 10.1080/00664677.2013.843444

Menghin, O. (1957). Estilos del arte rupestre de Patagonia. Acta Praehistorica I: 57-87.

Minnegal, M. (1995). A necessary unity: the articulation of ecological and social explanations of behavior. Man (NS) 2: 141-158. DOI: $10.2307 / 3034637$

Morphy, H. (1991). Ancestral Connections: Art and an Aboriginal System of Knowledge. Chicago, Chicago University Press.

Neme, G. y A. Gil (2008). Biogeografía humana en los Andes meridionales: tendencias arqueológicas en el sur de Mendoza. Chungara 40: 5-18. DOI: 10.4067/S0717-73562008000100002

Nielsen, A. E. (2006). Estudios internodales e interacción interregional en los Andes circumpuneños: Teoría, método y ejemplos de aplicación. En H. Lechtman (ed.), Esferas de interacción prehistóricas y fronteras nacionales modernas en los Andes sur centrales: 29-62. Lima, Instituto de Estudios Peruanos.

Nielsen, A. E. (2017). Comentario: actualidad y potencial de la arqueología internodal surandina. Estudios Atacameños Arqueología y Antropología Surandinas 56: 299-317. DOI: 10.4067/S0718-10432017000300012

Nielsen, A. E., J. Berenguer R. y G. Pimentel (2019). Inter-nodal archaeology, mobility, and circulation in the Andes of Capricorn during the Late Intermediate Period (AD 1000-1450). Quaternary International 533(20): 48-65. DOI: 10.1016/j.quaint.2018.09.044

Niemeyer, H. y L. Weisner (1972-73). Los petroglifos de la cordillera andina de Linares (Provincias de Talca y Linares, Chile). Actas del Sexto Congreso de Arqueología Chilena II: 405-470. Santiago de Chile, Editorial Universitaria, Universidad de Chile. 
Oyarzábal, M., J. Clavijo, L. Oakley, F. Biganzoll, P. Tognetti, P., I. Barberis, H. Maturo, M. Aragón, P. Campanello, D. Prado, M. Oesterheld y R. Leon (2018). Unidades de vegetación de la Argentina. Ecología Austral 28(1): 40-63. DOI: 10.25260/EA.18.28.1.0.399

Perez, S. I., M. Postillone, D. Rindel, D. Gobbo, P. González y V. Bernal (2016). Peopling time, spatial occupation and demography of late Pleistocene-Holocene human population from Patagonia. Quaternary International 425: 214-223. DOI: 10.1016/j.quaint.2016.05.004

Prates, L. (2008). Los indígenas del río Negro. Un enfoque arqueológico. Colección Tesis Doctorales. Buenos Aires, Sociedad Argentina de Antropología.

Re, A. (2010). Representaciones rupestres en mesetas altas de la provincia de Santa Cruz. Circulación de información en espacios de uso estacional. Tesis Doctoral inédita, Facultad de Filosofía y Letras, Universidad de Buenos Aires.

Re, A. y J. B. Belardi (2019). Pinturas rupestres y comunicación en la cuenca de los lagos Tar y San Martin (provincia de Santa Cruz). Revista del Museo de Antropología 12(1): 73-84. DOI: 10.31048/1852.4826. v12.n1.19051

Richerson, P. J. y R. Boyd (2005). Not by genes alone. How culture transformed human evolution. Chicago, University of Chicago Press.

Riris, P. y M. Arroyo-Kalin (2019). Widespread population decline in South America correlates with midHolocene climate change. Scientific Reports 9: 6850. DOI: 10.1038/s41598-019-43086-w

Rockman, M. (2003). Knowledge and Learning in the Archaeology of Colonization. En M. Rockman y J. Steele (eds.) Colonization of Unfamiliar Landscapes: The Archaeology of Adaptation: 3-24. Routledge, London.

Romero, G. y A. Re (2014). Representaciones rupestres del noreste de Neuquén (Patagonia septentrional). Primeras tendencias espaciales y temporales. Comechingonia. Revista de Arqueología 18(1): 73-92. DOI: 10.37603/2250.7728.v18.n1.27627

Romero Villanueva, G. (2016). La clasificación de las pinturas rupestres del noreste de Neuquén, Patagonia septentrional. En F. Oliva, A. M. Rocchietti y F. S. Banfi (eds.), Imágenes rupestres, lugares y regiones: 441-452. Rosario, Universidad Nacional de Rosario.

Romero Villanueva, G. (2019a). Biogeografía humana y circulación de información en el norte del Neuquén. Un análisis arqueológico sobre la comunicación visual en grupos cazadores-recolectores del noroeste de Patagonia. Tesis Doctoral inédita, Facultad de Filosofía y Letras, Universidad de Buenos Aires.

Romero Villanueva, G. (2019b). La contextualización temporal del arte rupestre de la Localidad BarrancasButa Ranquil (norte del Neuquén). Métodos, indicadores y aportes al poblamiento visual del noroeste de Patagonia. Trabajo presentado en el III Congreso Nacional de Arte Rupestre. CABA, Argentina.

Romero Villanueva, G. (2021). El arte rupestre de Cueva Huenul 1 (Neuquén, Argentina): un lugar persistente del noroeste de Patagonia. Estudios Atacameños. En prensa.

Romero Villanueva, G. y R. Barberena (2015). Diseños y soportes tardíos en Patagonia septentrional. Comparación entre arte rupestre y artefactos decorados del noreste del Neuquén (Argentina). En H. Collado Giraldo y J. J. García Arranz (eds.), Symbols in the Landscape: 735-742. Tomar, Instituto Terra e Memória.

Romero Villanueva, G. y R. Barberena (2017). Los huesos de guanaco pintados de Cueva Huenul 1 (norte del Neuquén, Patagonia septentrional). Relaciones 42(2): 369-377. 
Romero Villanueva, G. y R. Barberena (2021). Lugares, identidades e imágenes rupestres: una 'mirada exploratoria' desde los espacios internodales del noroeste de Patagonia. Congreso Nacional de Arqueología Chilena. En prensa.

Romero Villanueva, G., R. Gutiérrez, R. Campbell, R. Barberena y G. Lucero (2021d). Conectividad visual trasandina: una exploración del arte rupestre de paisajes cordilleranos y espacios adyacentes $\left(36^{\circ}-37^{\circ}\right.$ Lat. Sur) mediante análisis espaciales y de redes. XI Jornadas de Arqueología de la Patagonia. En prensa.

Romero Villanueva, G., G. Lucero y R. Barberena (2020). Andean summer-break: rock art insights on information networks and social interaction in a desert-highland interface in northern Patagonia (South America). Cuadernos de Arte Prehistórico. Volumen especial 1: 89-121.

Romero Villanueva, G., A. Rughini, J. Paiva, R. Garvey, A. Brera, C. Sánchez-Campoo, K. Borrazzo, C. Frigolé, A. Gasco, C. Llano, M. V. Fernández, R. Magliolo y R. Barberena (2021a). Historia ocupacional y organización espacial humana en Patagonia: una discusión desde Cueva Yagui (provincia del Neuquén, Argentina). Chungara. En evaluación.

Romero Villanueva, G., M. Sepúlveda y R. Barberena (2021c). Programa 'Microarqueología, arte y color en perspectiva multiescalar': objetivos, propuesta analítica y resultados esperados en el norte del Neuquén (Patagonia septentrional, Argentina). VIII Congreso Nacional de Arqueometría. En prensa.

Romero Villanueva, G., M. Sepúlveda, A. Cherkinsky, J. Cárcamo y R. Barberena (2021b). First direct AMS dating of northern Patagonia rock art (South America). Ms. En preparación.

Rughini, A., G. Romero Villanueva, G. Lucero, M. Cardillo, K. Borrazzo, M. V. Fernández, A. Brera, C. Frigolé, A. Castillo, M. Vitores, C. Llano, R. Garvey y R. Barberena (2020). Arqueología distribucional y biogeografía humana en un paisaje andino-patagónico. Latin American Antiquity31(3):595-614. DOI:10.1017/laq.2020.22

Scheinsohn, V. (2011). Rock Art Information among Hunter-Gatherers in Northwest Patagonia: An Assesment of Environmental and Territorial Models. En R. Whallon, W. A. Lovis y R. Hitchcock (eds.), Information and its Role in Hunter-Gatherer Bands: 235-247. Los Ángeles, UCLA Cotsen Institute of Archaeology Press.

Scheinsohn, V., C. Szumik, S. Leonardt y F. Rizzo (2009). Distribución espacial del arte rupestre en el bosque y la estepa del Norte de Patagonia. En M. Salemme, F. Santiago, M. Álvarez, E. Piana, M. Vázquez y M. E. Mansur (eds.), Arqueología de Patagonia. Una Mirada Desde el Último Confín: 541-560. Ushuaia, Editorial Utopías.

Scheinsohn, V y C. Szumik (2007). Distribuciones arqueológicas en la Patagonia Norte: una perspectiva biogeográfica. En F. Morello, M. Martinic, A. Prieto y G. Bahamonde (eds.), Arqueología de Fuego-Patagonia. Levantando piedras, desenterrando huesos... y develando arcanos: 109-116. Punta Arenas, Instituto de la Patagonia-Universidad de Magallanes y Fundación CEQUA.

Schlanger, S. (1992). Recognizing Persistent Places in Anasazi Settlement Systems. En L. Wandsnider y J. Rossignol (eds.), Space, Time and Archaeological Landscapes: 91-112. Nueva York, Plenum Press.

Schobinger, J. (1985). Áreas intermedias o marginales. En C. Gradin y J Schobinger (eds.), Cazadores de la Patagonia y agricultores andinos. Arte rupestre de la Argentina: 80-91. Madrid, Encuentro Ediciones.

Sepúlveda, M. (2009). Aspectos tecnológicos en la pintura. Reflexiones elaboradas a partir de análisis físico-químicos aplicados al estudio de las pinturas de la localidad del río Salado (II región, norte de Chile). En M. Sepúlveda, L. Briones y J. Chacama (eds.), Crónicas sobre la piedra: 199-218. Arica, Ediciones Universidad de Tarapacá.

Sepúlveda, M. (2020). Making visible the invisible. A microarchaeology approach and an Archaeology of 


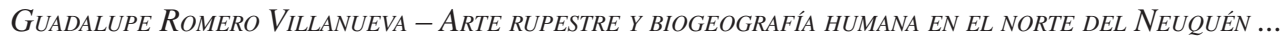

Color perspective for rock art paintings from the southern cone of South America. Quaternary International. DOI: 10.1016/j.quaint.2020.05.031

Sepúlveda, M., T. Saintenoy, L. Cornejo, C. Dudognon, F. Espinoza, Z. Guerrero-Bueno y E. Cerrillo-Cuenca (2019). Rock art painting and territoriality in the precordillera of northernmost Chile (South-Central Andes). Archeological and spatial approaches to the Naturalistic Tradition. Quaternary International 503(B):254263. DOI: 10.1016/j.quaint.2017.02.005

Taçon, P. (1994). Socialising landscapes: the long-term implications of signs, symbols and marks on the land. Archaeology in Oceania 29: 117-129. DOI: 10.1002/arco.1994.29.3.117

Taçon, P. S. C. y C. Chippindale (1998). An archaeology of rock-art through informed methods and formal methods. En C. Chippindale y P. S. C. Taçon, The archaeology of rock art: 1-10. Cambridge, Cambridge University Press.

Terrell, J. E. (2006). Human biogeography: evidence of our place in nature. Journal of Biogeography 33: 2088-2098. DOI: 10.1111/j.1365-2699.2006.01581.x

Timpson, A., R. Barberena, M. G. Thomas, C. Méndez y K. Manning (2021). Directly modelling population change in the South American Arid Diagonal using ${ }^{14} \mathrm{C}$ dates. Philosophical Transactions of the Royal Society B: 20190723. DOI: $10.1098 /$ rstb.2019.0723

Troncoso, A. (2006). Arte rupestre en la cuenca del río Aconcagua: formas, sintaxis, estilo, espacio y poder. Tesis Doctoral inédita. Departamento de Historia i Facultade de Xeografía e Historia, Universidade de Santiago de Compostela.

Troncoso, A. (2019). Rock Art, Historical Ontologies and the Genealogy of Landscape. A Case Study from the Southern Andes (30 lat. S). En M. C. Lozada y H. Tantaleán (eds.), Andean Ontologies: New Perspectives. Gainesville, United States: University Press of Florida. DOI: 10.5744/florida/9780813056371.003.0011

Troncoso, A., F. Moya y M. Basile (2016). Rock art and social networks among hunter gatherers of northcentral Chile. Journal of Anthropological Archaeology 42: 154-168. DOI: 10.1016/j.jaa.2016.04.007

Veth, P. M. (1993). Islands in the Interior. The Dynamics of Prehistoric Adaptations within the Arid Zone of Australia. Ann Arbor, International Monographs in Prehistory.

2005. Cycles of aridity and human mobility: Risk minimization among late Pleistocene foragers of the Western Desert, Australia. En P. Veth, M. Smith y P. Hiscock (eds.), Desert Peoples. Archaeological Perspectives: 100-115. Oxford, Blackwell Publishing Ltd.

Walker, J. H. (2012). Recent Landscape Archaeology in South America. Journal of Archaeological Research 20: 309-355. DOI: 10.1007/s10814-012-9057-6

Whallon, R. (2006). Social networks and information: Non-“utilitarian" mobility among hunter-gatherers. Journal of Anthropological Archaeology 25(2): 259-270. DOI: 10.1016/j.jaa.2005.11.004

Whallon, R. (2011). An Introduction to Information and Its Role in Hunter-Gatherer Bands. En R. Whallon, W. A. Lovis y R. Hitchcock (eds.), Information and its Role in Hunter-Gatherer Bands: 1-27. Los Ángeles, UCLA Cotsen Institute of Archaeology Press.

Whitley, D. S. (2001). Handbook of Rock Art Research. UK, Altamira Press.

Wiessner, P. (1983). Style and social information in Kalahari San projectile points. American Antiquity 48(2): 253-276. DOI: $10.2307 / 280450$ 
Relaciones de la Sociedad Argentina de Antropología 46 (2), julio-diciembre 2021: 595-628

Winterhalder, B. y E. Smith (1991). Evolutionary ecology and the social sciences. En E. Smith y B. Winterhalder (eds.), Evolutionary Ecology and Human Behavior: 3-23. New York, Aldine de Gruyter.

Winterhalder, B. y E. Smith (2000). Analyzing adaptive strategies: Human behavioral ecology at twenty-five. Evolutionary Anthropology 9:51-72.DOI: 10.1002/(SICI)1520-6505(2000)9:2<51::AID-EVAN1>3.0.CO;2-7

Wobst, M. (1977). Stylistic behavior and information exchange. En C. E. Cleland (ed.), For the director: research essays in honor of James B. Griffin: 317-342. Ann Arbor, University of Michigan.

Wylie, A. (2002). Archaeological Cables and Tacking: Beyond Objectivism and Relativism. En A. Wylie (comp.), Thinking from Things: Essays in the Philosophy of Archaeology: 161-167. Berkeley, University of California Press.

Zeanah, D. (2004). Sexual Division of Labor and Central Place Foraging: A Model for the Carson Desert of Western Nevada. Journal of AnthropologicalArchaeology 23(1): 1-32. DOI: 10.1016/S0278-4165(03)00061-8 